\title{
Testing linear gravity wave theory with simultaneous wind and temperature data from the mesosphere
}

\author{
Manja Placke*, Peter Hoffmann, Michael Gerding, Erich Becker, Markus Rapp ${ }^{1}$ \\ Leibniz Institute of Atmospheric Physics at the Rostock University, Kühlungsborn, Germany
}

\section{A R T I C L E I N F O}

\section{Article history:}

Received 8 August 2012

Received in revised form

15 November 2012

Accepted 22 November 2012

Available online 7 December 2012

Keywords:

Gravity waves

Middle atmosphere dynamics

Observations and model data

\begin{abstract}
A B S T R A C T
Linear gravity wave (GW) theory is tested on the basis of simultaneous measurements of horizontal winds from a medium frequency (MF) radar at Juliusruh $\left(54.6^{\circ} \mathrm{N}, 13.4^{\circ} \mathrm{E}\right)$ and temperatures from combined Potassium (K) and Rayleigh-Mie-Raman (RMR) lidars at Kühlungsborn $\left(54.1^{\circ} \mathrm{N}, 11.8^{\circ} \mathrm{E}\right)$. The applicability of linear GW theory to mesospheric observations is far from obvious given the fact that typically a whole spectrum of waves is observed which may interact non-linearly. Before analyzing our experimental dataset for its fit to expectations from linear GW theory, the chosen methodology is tested with model data from the Kühlungsborn Mechanistic general Circulation Model (KMCM). This model is a mechanistic general circulation model with high spatial resolution such that waves with horizontal wavelengths in excess of $\sim 350 \mathrm{~km}$ are explicitly resolved yielding a semi-realistic wave motion field. This may be considered as a suitable test-bed for defining and optimizing wave analysis approaches. This effort reveals that Stokes parameters analysis of filtered time series of GW-induced wind and temperature fluctuations in comparison to wave amplitudes directly retrieved from the filtered time series allows us to demonstrate the validity of polarization relations based on linear wave theory. Indeed, applying the same methodology to the observations yields similarly conclusive results thus giving evidence for the applicability of linear wave theory to mesospheric observations after appropriate filtering. These investigations are complemented by a comparison of kinetic and potential energy per unit mass for model and measured data. This reveals that the ratio of kinetic and potential energy also roughly follows expectations from linear wave theory.
\end{abstract}

(c) 2012 Elsevier Ltd. All rights reserved.

\section{Introduction}

The understanding of gravity waves (hereafter: GW) is an important topic as these waves are crucial for the structure, dynamics, and variability of the middle atmosphere (e.g., Fritts and Alexander, 2003). In particular, GW have a significant influence on atmospheric circulation patterns as they transport momentum and energy and deposit it far away from their source regions. Here we focus on the investigation of GW in the mesosphere and lower thermosphere (MLT) region. At these altitudes, GW can be identified by wind and temperature fluctuations as measured by radars (e.g., Vincent and Fritts, 1987), lidars (e.g., Rauthe et al., 2006; Gerding et al., 2008), ground based observations of airglow (e.g., Nakamura et al., 1999), and by satellite instruments (e.g., Preusse et al., 2000; Ern et al., 2011). The main aim of the present study is to test the applicability of linear GW theory by checking the polarization relations between measured

\footnotetext{
* Corresponding author. Tel.: +49 38293 68204; fax: +49382936850.

E-mail address: placke@iap-kborn.de (M. Placke).

${ }^{1}$ Now at Institute of Atmospheric Physics, German Aerospace Center (DLR), Oberpfaffenhofen, Germany.
}

winds and temperature which had firstly been introduced by Hines (1960) and specified by Gossard and Hooke (1975) and between the kinetic and potential energy of the identified GW. In the mesosphere often a single dominant GW is observed. Nevertheless, the validity of linear wave theory is far from obvious. Multiple waves could be present at the same time but not be observed or identified due to limitations of the observing systems. In some cases indications for resonant wave-wave interactions have been observed (Wüst and Bittner, 2006, and references therein). Further, in the MLT region the generation of secondary waves due to breaking of the primary waves has been suggested (Fritts and Alexander, 2003; Chun and Kim, 2008; Vadas et al., 2009).

While the literature is very rich on experimental studies of mesospheric GW (see Fritts and Alexander, 2003, and the many references therein), only few studies have so far considered both wind and temperature fluctuations at the same time. One of the first common observations of GW perturbations of wind and temperature in the mesopause region was done by She et al. (1991) using a Na-lidar, where they showed a direct link between mean temperature and wind variations and their vertical shear variances. In a later paper, She and Yu (1994) analyzed 
propagating waves in individual profiles of simultaneous wind and temperature variations and found the same downward phase velocity in both sets of profiles. Recently, Suzuki et al. (2010) compared simultaneous airglow, lidar and radar measurements to identify short period mesospheric GW over Japan with the MU radar and a sodium lidar for a case study. In addition, Gardner and Liu (2007) investigated seasonal variations of vertical fluxes of heat and momentum and their relation to GW activity by using lidar observations of wind and temperature profiles in the mesosphere at the Starfire Optical Range. Obviously, the knowledge of these fluxes is essential for a quantitative understanding of the momentum and heat balance of the MLT, and ideally such data should be available on global scales. However, at present, global scale momentum fluxes may only be indirectly derived from temperature fluctuations. For example, Ern et al. (2004) analyzed temperature variations obtained with the Cryogenic Infrared Spectrometers and Telescopes for the Atmosphere (CRISTA) and obtained global fields of the absolute values of GW momentum fluxes in the stratosphere assuming that the analyzed waves were monochromatic and linear. Since then, this technique has been applied in several subsequent studies (see Alexander et al., 2010, and references therein). Recently, GW momentum fluxes have also been derived from satellite data for the first time in the MLT region (Ern et al., 2011). However, so far a definitive justification for the made assumptions is lacking for observations in the MLT. It is hence the major objective of this paper to test these assumptions using combined radar and lidar observations.

In the present paper wave structures in the horizontal wind and temperature field obtained with a ground based MF (=medium frequency) radar and the combination of a RMR (= Rayleigh-MieRaman) and a K-resonance lidar are investigated. Before analyzing our experimental dataset for its fit to expectations from linear GW theory, the chosen methodology is tested with model data from the Kühlungsborn Mechanistic general Circulation Model (KMCM). This model is a mechanistic general circulation model with high spatial resolution such that waves with horizontal wavelengths in excess of $\sim 350 \mathrm{~km}$ are explicitly resolved yielding a semi-realistic wave motion field. This may be considered as an ideal test-bed for defining and optimizing wave analysis approaches.

The paper is organized as follows. In Section 2, the radar and lidar instruments as well as the KMCM are briefly described. Section 3 describes the chosen methodology (including issues of wavelet analysis, time series filtering, wave parameter analysis, polarization relations, as well as determination of potential and kinetic energies) which is first tested with model data (Section 3.1) and then applied to our radar and lidar observations (Section 3.2). Finally, in Section 4 the paper is concluded by summarizing the obtained results.

\section{Experimental and model details}

\subsection{Radar and lidar instruments}

For the experimental investigations, MF radar measurements at Juliusruh $\left(54.6^{\circ} \mathrm{N}, 13.4^{\circ} \mathrm{E}\right)$ as well as $\mathrm{K}$ and RMR lidar measurements at Kühlungsborn $\left(54.1^{\circ} \mathrm{N}, 11.8^{\circ} \mathrm{E}\right)$ have been considered. The two sites are situated almost at the same latitude and have a horizontal distance of about $120 \mathrm{~km}$. This is reasonably close for a comparative $\mathrm{GW}$ analysis with the different instruments provided that the horizontal wavelength of a considered wave is large compared to this distance.

The MF radar is an excellent instrument for the continuous monitoring of atmospheric dynamics (i.e., winds, tides, planetary waves, and internal GW). At Juliusruh, MF radar measurements have been performed since 1990 . The MF radar for the present study uses a Mills-Cross antenna consisting of 13 crossed dipoles for the transmission of radio wave pulses of $4 \mathrm{~km}$ length. It has been running within this configuration continuously since 2005 at a frequency of $3.18 \mathrm{MHz}$ and is working with a peak pulse power of $128 \mathrm{~kW}$. The atmospheric echoes are sampled with a vertical resolution of $2 \mathrm{~km}$ by three crossed horizontal dipoles which are arranged as a triangle. Further information about the MF radar can be found in Keuer et al. (2007). From the MF radar observations, the mesospheric wind field is by default estimated in the height range from about 70-96 km using a cross correlation analysis of the signals received at the spatially separated antennas. For the case studies here, the lower altitude limit has been extended down to $60 \mathrm{~km}$ height. The statistical uncertainty of the wind values is in the order of $2 \mathrm{~m} / \mathrm{s}$ (e.g., Gonzalez et al., 1994).

The $\mathrm{K}$ lidar determines temperatures from the Doppler broadening of the backscattered resonance signal between about 85 and $105 \mathrm{~km}$. With the RMR lidar the Rayleigh backscatter is detected from the ground up to about $90 \mathrm{~km}$ from which atmospheric density profiles can be determined and converted to temperature by hydrostatic integration with the $\mathrm{K}$ lidar providing the start value at about $89 \mathrm{~km}$. The combination of both systems allows the worldwide unique possibility to measure vertical temperature profiles and temperature variations due to waves in the whole altitude range from 1 to $105 \mathrm{~km}$. The used temporal and vertical resolutions are between $10 \mathrm{~min}$ and $1 \mathrm{~h}$ and about $1 \mathrm{~km}$, respectively. Thereby the statistical uncertainty of the temperature measurements is typically $1.5-2.5 \mathrm{~K}$. A detailed description of these combined lidar measurements is given in Alpers et al. (2004). With lidar measurements, wave-induced temperature fluctuations can be studied from the ground up to the MLT region, and have been used for example for long-term temperature observations (Gerding et al., 2008) and the seasonal variation of GW properties (Rauthe et al., 2008).

For the wind and temperature analysis in this paper the data of both radar and lidar measurements has been prepared in the same way using averages over $2 \mathrm{~h}$ which have been shifted by $30 \mathrm{~min}$. These sliding averages serve as a kind of low pass filtering in order to suppress high frequency variations, to avoid small gaps, and to get a slight smoothing of the data to focus on the general structure of GW with periods investigated here. The height resolution of temperature and wind data is $1 \mathrm{~km}$ and $2 \mathrm{~km}$, respectively. While the radar measurements are continuous above $80 \mathrm{~km}$ and thus give long consecutive time series, the lidar measurements are temporally limited especially to dark and cloudless conditions. For our purpose, i.e., the wave analysis of combined simultaneous wind and temperature data, a dataset with a long continuous lidar time series is required. This is for instance the case for the period of 11-13 October 2005 which was part of the international CAWSES tidal campaign (for details see Ward et al., 2010) where a continuous lidar time series of three consecutive days exists. This dataset will be investigated here in detail.

\subsection{The Kühlungsborn Mechanistic general Circulation Model (KMCM)}

In support of the above experiments, we further make use of the GW-resolving mechanistic general circulation model KMCM. KMCM has been designed to investigate the global atmospheric dynamics at high resolution and is based on a standard spectral dynamical core. The concept of the used model version is described in detail in Becker (2009). The model setup for our current purpose is identical to that used in Placke et al. (2011), i.e., the data is for permanent January conditions with 190 hybrid levels from the surface to about $125 \mathrm{~km}$, resulting in a level spacing of approximately $600 \mathrm{~m}$ from the boundary layer to about $105 \mathrm{~km}$. Furthermore, the model uses a triangular truncation 
at total wavenumber 120 (T120). Hence, the medium frequency part of the GW spectrum, i.e., waves with a minimum horizontal wavelength of $350 \mathrm{~km}$ are resolved. Since these waves are subject to an enhanced parameterization of turbulence, they interact nonlinearly with the large-scale flow according to the non-acceleration theorem. In particular, a realistic strength of the GW drag and turbulent dissipation rate in the MLT is simulated. Note that the frequency-wavenumber spectrum in KMCM is generally broad in the MLT (see Fig. 7a in Becker, 2009). Furthermore, resolved variances are in good agreement with observations at high and midlatitudes (Hoffmann et al., 2010).

The model output is on the model's hybrid surfaces for arbitrary longitude-latitude grids with a snapshot interval of $11.25 \mathrm{~min}$. One of the advantages of the KMCM in the present version for the investigation of $\mathrm{GW}$ is the non-existence of tidal influences. This is due to the fact that the model is a mechanistic primitive equation model which here has been used with a simple radiation scheme in the form of a Newtonian temperature relaxation toward a constant radiative equilibrium background temperature (see Becker, 2009, and references therein). The model can, however, also be extended by a simple excitation of tides (Becker, 2011).

\section{Gravity wave analysis for model data and an experimental case study}

\subsection{Investigation of KMCM winds and temperature}

Horizontal winds and temperature from the wave-resolving KMCM present a good basis to test and optimize GW analysis methods for the verification of the predictions of the linear theory such as the polarization relations between wind and temperature variation. Further, the relation between kinetic and potential energy can be investigated. For the following analysis, 10 consecutive model days for permanent January conditions have been arbitrarily chosen for a position of $54^{\circ} \mathrm{N}$ and $12^{\circ} \mathrm{E}$ representing the observational midlatitude locations Juliusruh and Kühlungsborn.

\subsubsection{Time series analysis for KMCM}

A 10-day case study of model data has been considered with calculated time averages over $2 \mathrm{~h}$, shifted by half an hour, and 61 height intervals of $1 \mathrm{~km}$ vertical extent each from 50 to $110 \mathrm{~km}$. Deviations from the 10-day mean per height are calculated for horizontal winds and temperature. The height-time crosssections of the zonal wind deviation $u^{\prime}$, the meridional wind deviation $v^{\prime}$ and the temperature deviation $T^{\prime}$ are displayed in Fig. 1. It is clearly visible that the model resolves intensive waves with wind variation amplitudes of about $50 \mathrm{~m} / \mathrm{s}$ and temperature variation amplitudes of about $25 \mathrm{~K}$ between 50 and $100 \mathrm{~km}$. The strongest wave-like events are visible in the mesopause region from about $85 \mathrm{~km}$ to $100 \mathrm{~km}$. The vertical gradients of wave phase lines in the wind and temperature field become steeper from lower to higher altitudes. The corresponding changes in the vertical wavelength arise due to changes of the background wind which in turn cause changes of the intrinsic horizontal phase speeds (Eckermann, 1995). In addition, critical level filtering changes the GW spectrum with increasing height.

Dominant wave periods have been determined in the wind and temperature field time series at $92 \mathrm{~km}$ height where in general the strongest wave structures occur. Note that the same altitude will be used for common radar and lidar observations later on in Section 3.2.1. The wavelet power spectra, as for instance described in Serafimovich et al. (2005) and Torrence and Compo (1998), are shown in Fig. 2 for the zonal wind (a), meridional wind (b), and temperature (c) variations for wave
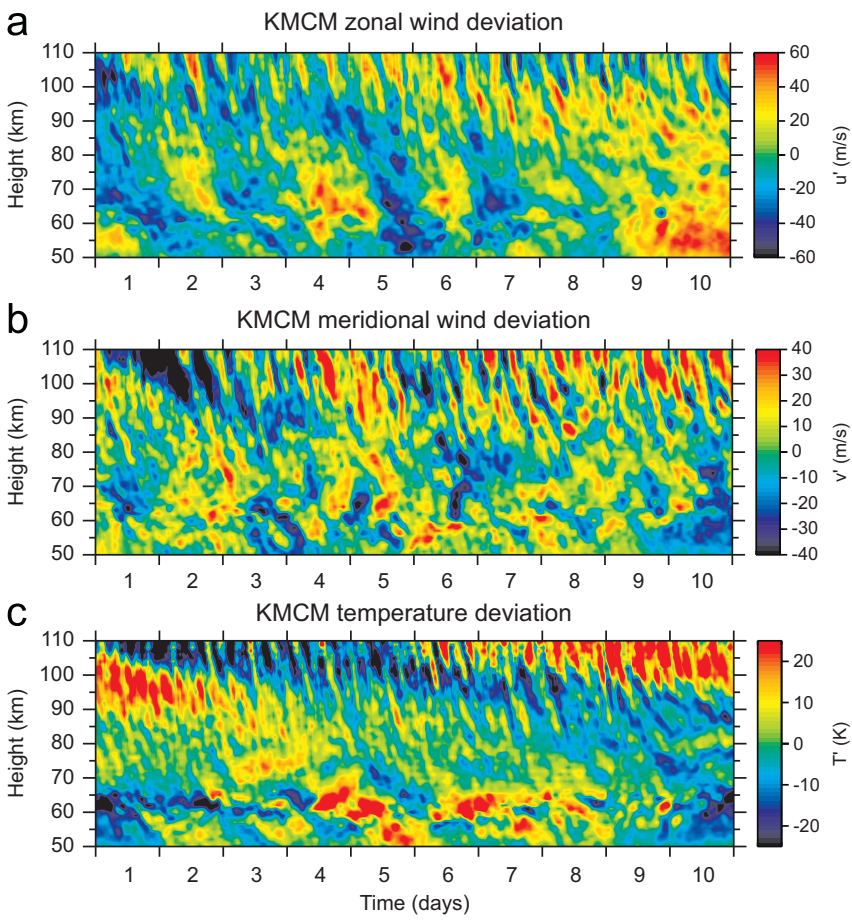

Fig. 1. Height-time cross-sections of the zonal wind (a), meridional wind (b), and temperature (c) variations from the KMCM for the geographical position $54^{\circ} \mathrm{N}$ and $12^{\circ} \mathrm{E}$. The data has a time resolution of $30 \mathrm{~min}$, integrated for $2 \mathrm{~h}$. The height resolution is $1 \mathrm{~km}$.

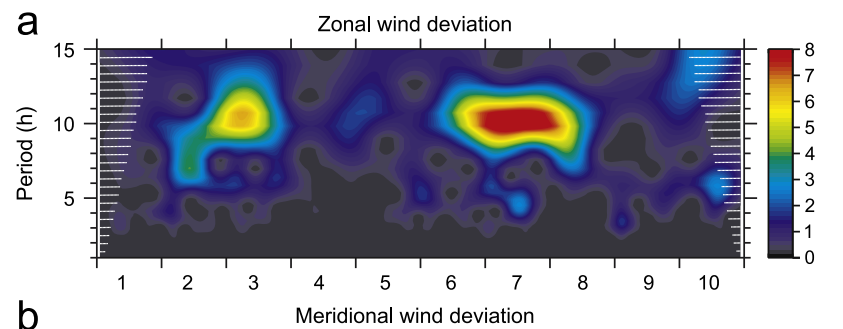

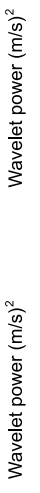
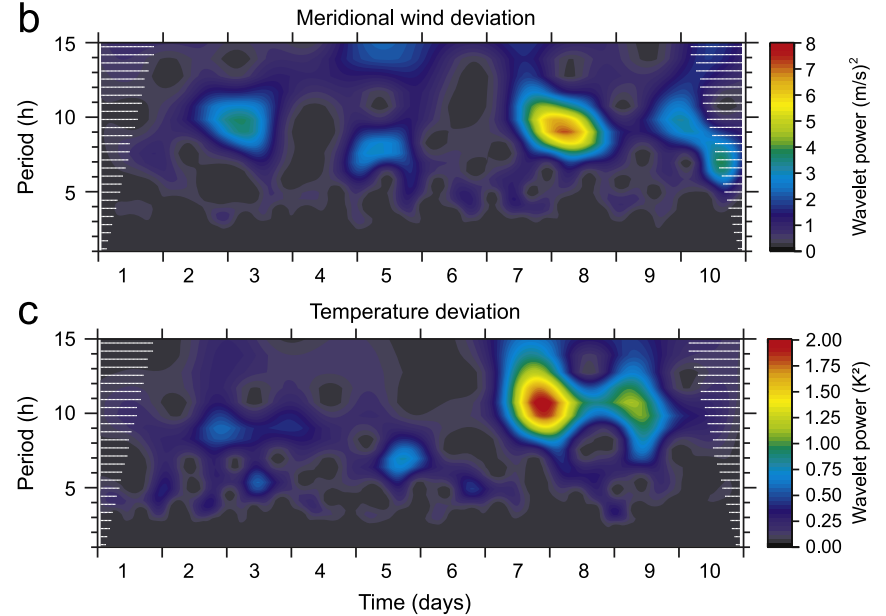

Fig. 2. Spectra of the zonal wind (a), meridional wind (b), and temperature (c) variations at $92 \mathrm{~km}$ height for KMCM derived with the wavelet transformation. The white shading indicates the cone of influence where boundary effects occur at the beginning and ending of the time series.

periods of up to $15 \mathrm{~h}$ over the 10 days. For all parameters, the major maximum is visible at day 7 until the mid of day 8 with a period between about 7 and $12 \mathrm{~h}$. The spectra of the meridional 

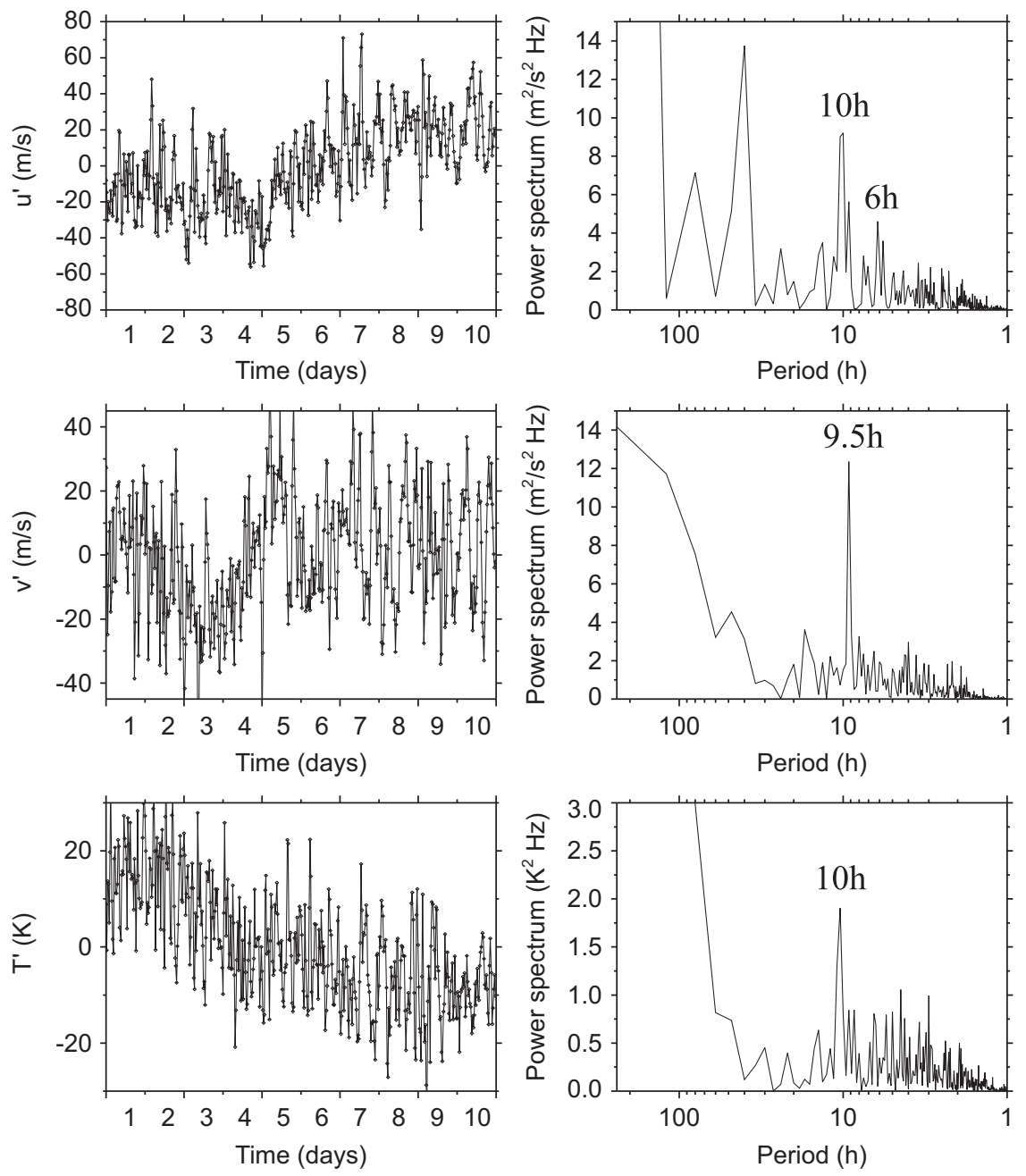

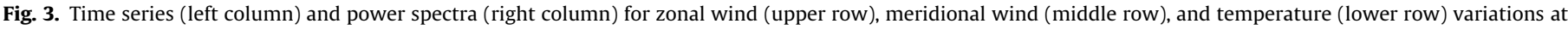
$92 \mathrm{~km}$ height for KMCM. Dominant peaks of the power spectra are labeled.

wind and temperature variations fit best to each other. While the major maximum extends over the whole day 7 for the zonal wind variations, it does not start until the mid of day 7 in the meridional wind and temperature variations.

As a next step, the power spectra for the wind and temperature variations at $92 \mathrm{~km}$ have been considered (Fig. 3). They all show similar dominant periods with maxima at about $9-10 \mathrm{~h}$ as well as peaks in the lower period range. Filtering the time series for the period band of strongest wave periods from the wavelet analysis (between 7 and $12 \mathrm{~h}$ ) at $92 \mathrm{~km}$ (Fig. 4) reveals that during the strongest wavelet power events like at the transitions from day 2 to day 3 and from day 7 to day 8 the zonal and meridional wind variations are $90^{\circ}$ phase-shifted as expected from linear GW theory. At the same time, the filtered meridional wind and temperature variations have a phase shift of $180^{\circ}$. Thus also the zonal wind and the temperature variations have a $90^{\circ}$ phase shift. These considerations will next be extended in the frame of a Stokes parameters analysis.

\subsubsection{Validity of polarization relations for KMCM data}

The aim of this section is a statistical evaluation of the polarization relations between wind and temperature variations. For this purpose, results obtained from the amplitudes of the filtered time

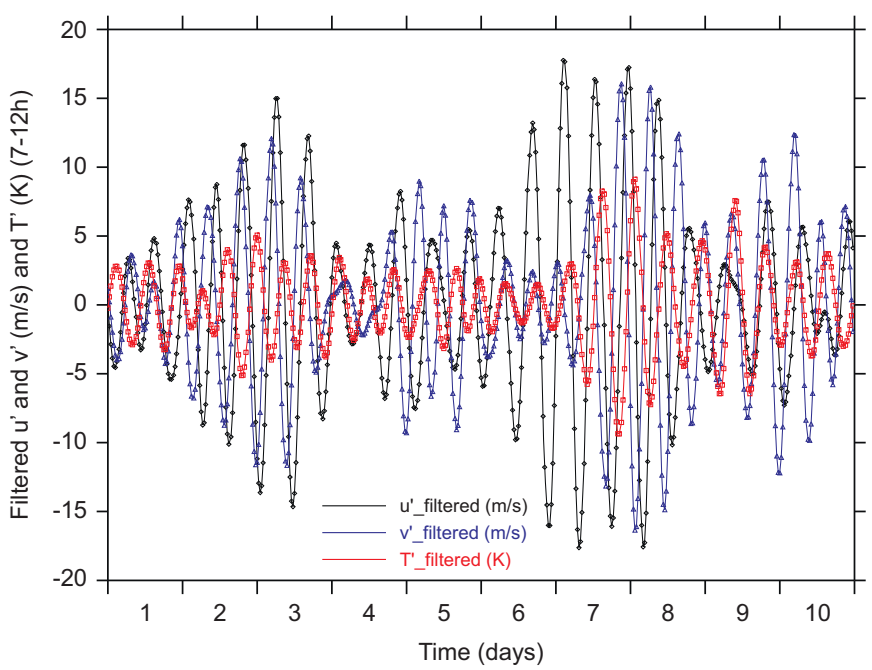

Fig. 4. Filtered time series for $7-12 \mathrm{~h}$ for zonal wind variations $u^{\prime}$ (black line), meridional wind variations $v^{\prime}$ (blue line), and temperature variations $T^{\prime}$ (red line) at $92 \mathrm{~km}$ height for KMCM. During the time with strongest amplitudes (day 2-3 and day 7-8) $u^{\prime}$ and $v^{\prime}$ are $90^{\circ}$ phase-shifted and $v^{\prime}$ is proportional to $-T^{\prime}$. (For interpretation of the references to color in this figure caption, the reader is referred to the web version of this article.) 
series in the previous section will be compared with calculations of wave parameters from a Stokes parameters analysis as introduced by Vincent and Fritts (1987) and extended to an analysis in the spectral domain by Eckermann and Vincent (1989). In our case, a Stokes parameters spectral analysis of 30-min mean wind vertical profiles (wind variations after band pass filtering with the bandwidths of 7-12 $\mathrm{h}$ in time) has been performed for the 10 model days following the procedure outlined in Serafimovich et al. (2005) and Serafimovich et al. (2006). The chosen height range covers $80-99 \mathrm{~km}$ where the largest wave structures are evident in Fig. 1. Note that this is also the altitude range where radar and lidar observations show maximum amplitudes. From the vertical profiles the Stokes parameters (total variance $I=\overline{u^{\prime 2}}+\overline{v^{\prime 2}}$, axial anisotropy $D=\overline{u^{\prime 2}}-\overline{v^{\prime 2}}$, "in-phase" covariance $P=2 \overline{u^{\prime} v^{\prime}}$ which is associated with linear polarization, and "in quadrature" covariance $Q=\widehat{\widehat{u}} \widehat{v} \sin \delta$ associated with circular wave polarization) have been determined for each time interval. Here $\widehat{u}$ and $\widehat{v}$ are the peak amplitudes of $u^{\prime}$ and $v^{\prime}, \delta$ is the polarization angle $\left(\delta=0^{\circ}\right.$ or $180^{\circ}$ implies linear polarization, $\delta=90^{\circ}$ or $270^{\circ}$ implies circular polarization, and anything between elliptical polarization), and overbars indicate vertical averages over the full wave period in height. The parameter $I$ is the sum of the horizontal wind variances and is hence a measure of the GW activity. From the Stokes parameters, the degree of the wave polarization $d$ between zonal and meridional wind fluctuation has been calculated

$d=\frac{\left(D^{2}+P^{2}+Q^{2}\right)}{I}$

as well as the averaged axial ratio of the wave ellipse

$R=\tan \mu$

with

$\mu=\frac{1}{2} \cdot \arcsin \left(\frac{Q}{d \cdot I}\right)$ and the wave propagation direction

$\Theta=\frac{1}{2} \cdot \arctan \left(\frac{P}{D}\right)$

(see Eckermann, 1996, for more details).

In Fig. 5, the temporal development of the mean distribution of the GW propagation direction (a), the mean normalized wave intensity $I$ (b) as well as the degree of polarization $d$ and the mean ellipse axial ratio $R$ (c) are shown for the time range of strongest wave activity (transition from day 7 to day 8). From (a) it can be seen that the waves propagate mainly in north-southern direction and that the normalized wave intensity (b) is almost constant. With a mean phase difference of $93.7^{\circ}$, the fluctuating zonal and meridional wind component closely follow the expectation from linear GW theory. The derived mean ellipse axial ratio (c) varies between about 0.4 and 0.9. From the axial ratio $R$ the intrinsic frequency $\omega$ has been estimated ( $\omega=f / R$ with $f$ being the Coriolis frequency). For the further statistical analysis, we only considered waves with $I>0.4$ and an axial ratio $R>0.3$ corresponding to intrinsic periods between 4.5 and $14.8 \mathrm{~h}$. Then the horizontal and vertical wave numbers $k_{h}$ and $m$ can be estimated making use of the Doppler equation

$k_{h}=\frac{\omega_{o b s}-\omega}{\overline{u_{h}}}$

with the observed frequency $\omega_{o b s}$ and the mean horizontal wind in the direction of the wind propagation $\overline{u_{h}}$ as well as the dispersion relation

$\omega^{2}=f^{2}+\frac{N^{2} k_{h}^{2}}{m^{2}}$

for inertia GW $\left(N^{2} \gg \omega^{2}\right)$ with $N$ being the Brunt-Väisälä frequency. Here the observed wave period of $10 \mathrm{~h}$ has been used based on the spectral analyses shown in Fig. 3. With the wave orientation $\Theta$ the zonal and meridional wave number $k$ and $l$ can be determined from

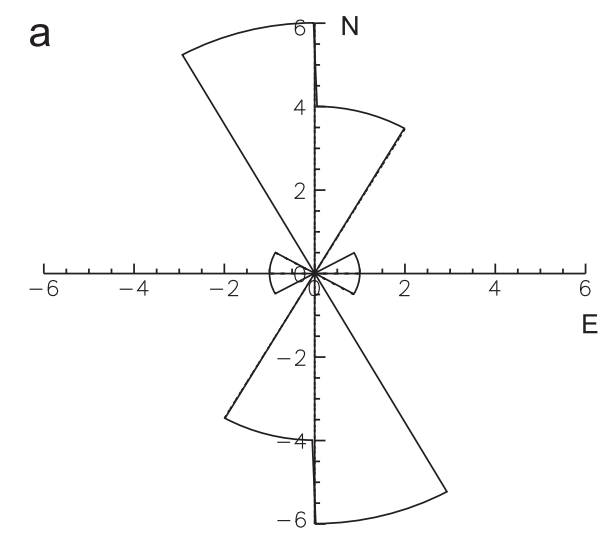

Mean ellipse axial ratio $\mathrm{R}=0.65$

Mean major axis orientation $=91.41^{\circ}$

Mean degree of polarization $d=0.49$

Mean phase difference $=93.69^{\circ}$

b

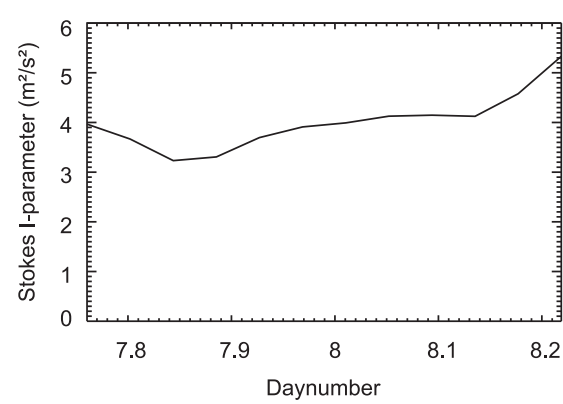

C

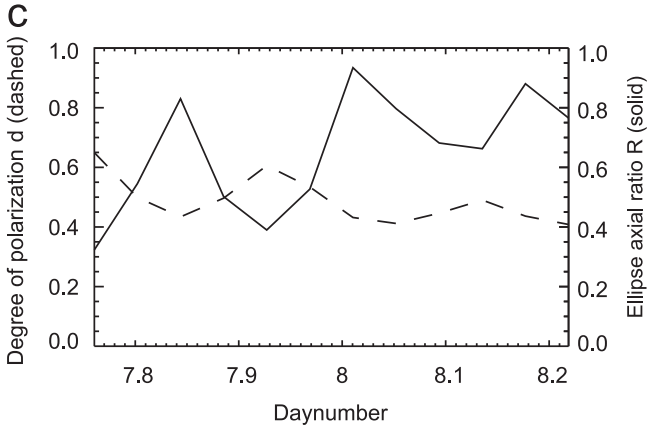

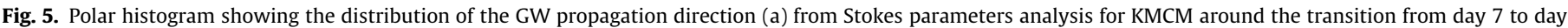

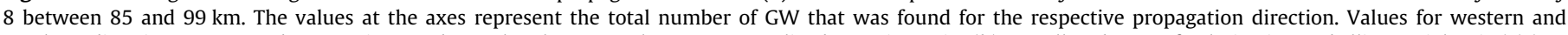

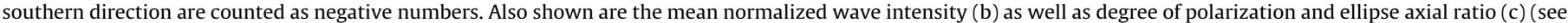
text for more information). 
the horizontal wave number $k_{h}$. With these parameters at hand, we may now evaluate the validity of the polarization relations. Suitable expressions for $T^{\prime} / u^{\prime}$ and $T^{\prime} / v^{\prime}$ can be derived from the well known relation between $T^{\prime}$ and the mean background temperature $T_{m}$ (e.g., Zink, 2000):

$\frac{T^{\prime}}{T_{m}}=i \frac{N^{2}\left(k^{2}+l^{2}\right)}{m g} \cdot \frac{1}{\omega k+i l f} \cdot u^{\prime}$
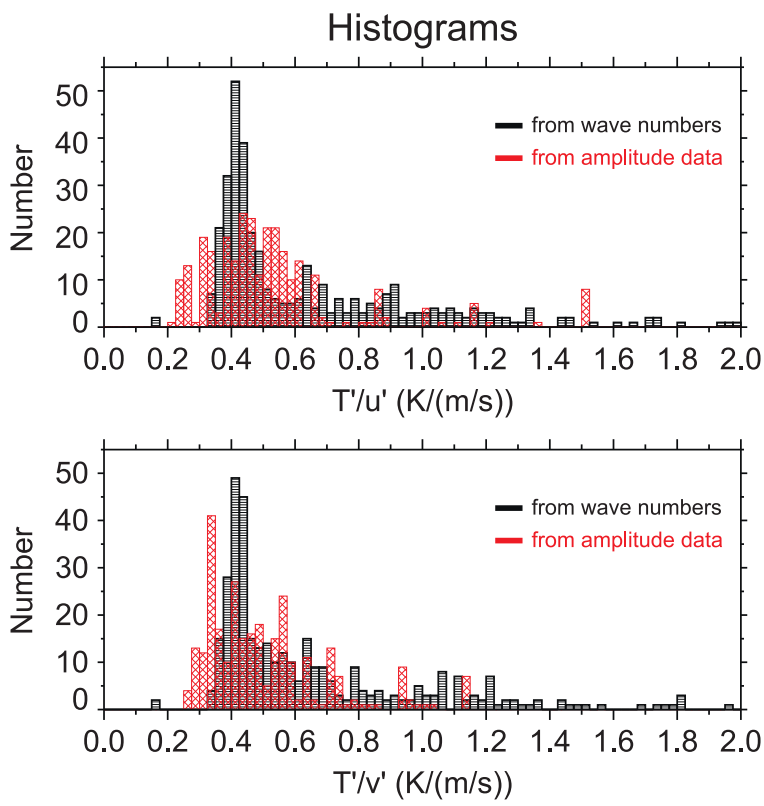

Fig. 6. Histograms of the polarization relations $T^{\prime} / u^{\prime}$ (upper panel) and $T^{\prime} / v^{\prime}$ (lower panel) for the $10 \mathrm{KMCM}$ model days. The black histograms show results calculated after Eqs. (8) and (10) from the wave numbers which have been determined from Stokes parameters analysis. The red histograms are calculations of $T^{\prime} / u^{\prime}$ and $T^{\prime} / v^{\prime}$ from the 12-h peak amplitudes of the filtered wind and temperature values from Fig. 4 . (For interpretation of the references to color in this figure caption, the reader is referred to the web version of this article.)
Here $g$ is the gravity acceleration. Thus the polarization relation between temperature and zonal wind variation can be calculated from

$\frac{T^{\prime}}{u^{\prime}}=i \frac{N^{2}\left(k^{2}+l^{2}\right)}{m g} \cdot \frac{T_{m}}{\omega k+i l f}$

The ratio of the zonal to the meridional wind fluctuation is

$v^{\prime}=\frac{l \omega-i k f}{k \omega+i l f} \cdot u^{\prime}$

so that the polarization relation between temperature and meridional wind variations is

$\frac{T^{\prime}}{v^{\prime}}=i \frac{N^{2}\left(k^{2}+l^{2}\right)}{m g} \cdot \frac{T_{m}}{\omega l-i k f}$.

The value of the mean squared Brunt-Väisälä frequency $N^{2}$ and the vertical mean temperature $T_{m}$ have been calculated for the height range of the Stokes parameters analysis (between 80 and $99 \mathrm{~km}$ ) with $N^{2}=4.13 \times 10^{-4} \mathrm{~s}^{-2}$ and $T_{m}=208.57 \mathrm{~K}$. The gravity acceleration $g$ is estimated to $9.53 \mathrm{~m} \mathrm{~s}^{-2}$ as a mean value for the considered height range, the Coriolis frequency $f$ is $\sim 0.000118 \mathrm{~s}^{-1}$ for the latitude $54^{\circ} \mathrm{N}$.

The statistical investigation of the polarization relations between wind and temperature for the 10 model days is shown in Fig. 6. The results obtained from the right hand sides of Eqs. (8) and (10) are displayed as black histograms showing most frequent values for $T^{\prime} / u^{\prime}$ and $T^{\prime} / v^{\prime}$ between about $0.3-0.6 \mathrm{~K} /(\mathrm{m} / \mathrm{s})$ with the main peaks for $0.4-0.45 \mathrm{~K} /(\mathrm{m} / \mathrm{s})$. The values from the 12-h peak amplitudes (i.e., left hand sides of the same equations), shifted by $30 \mathrm{~min}$, of the filtered wind and temperature time series are shown as red histograms. They have a broader distribution of values around the peak of the black histograms with most frequent values between 0.2 and $0.6 \mathrm{~K} /(\mathrm{m} / \mathrm{s})$. For $T^{\prime} / u^{\prime}$ the histogram peaks in about $0.45-0.5 \mathrm{~K} /(\mathrm{m} / \mathrm{s})$ which is very close to the results from the wave numbers. For $T^{\prime} / v^{\prime}$ the highest peak at about $0.35 \mathrm{~K} /(\mathrm{m} / \mathrm{s})$ lies somewhat beside the main peak of the histogram obtained from the wave numbers, but in general both histograms are also in reasonable agreement.
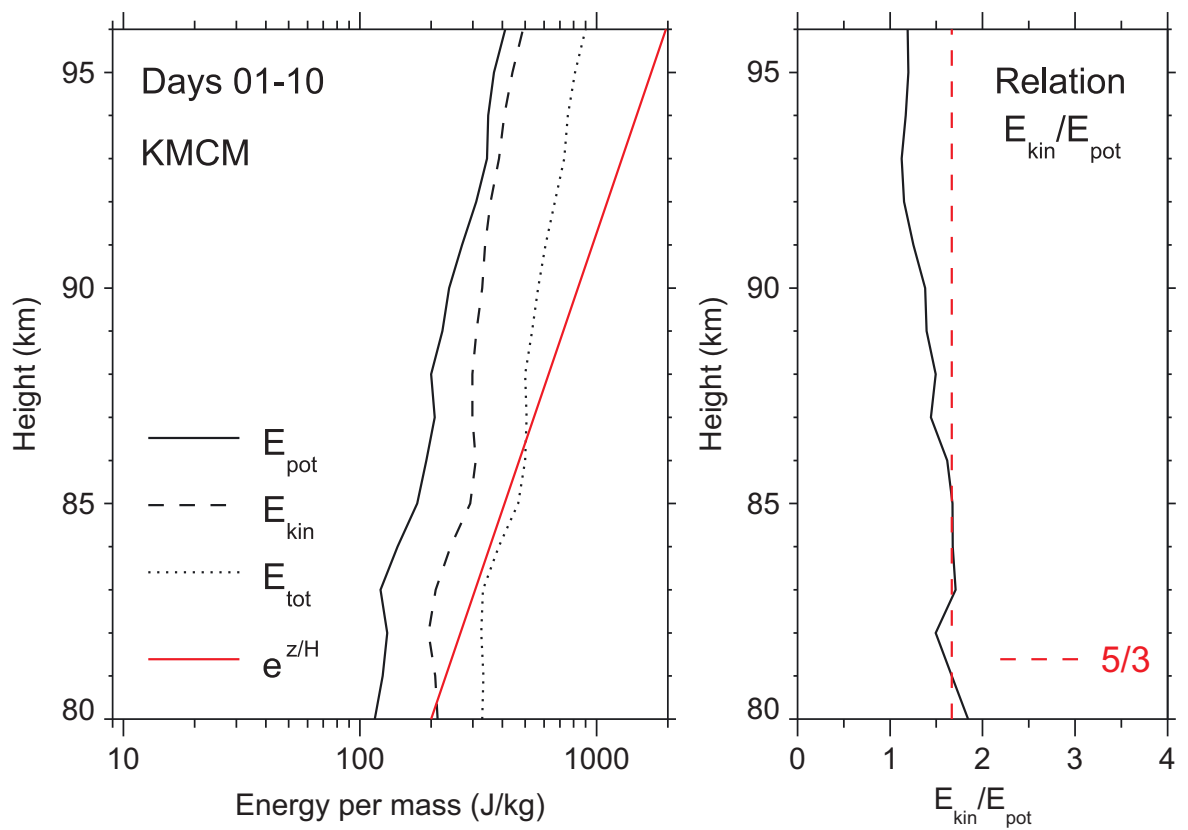

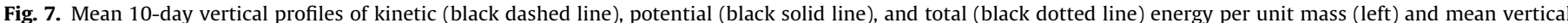

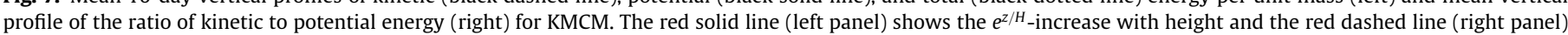

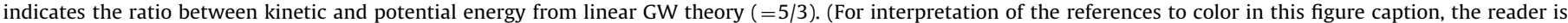
referred to the web version of this article.) 


\subsubsection{Kinetic and potential energy for gravity waves in KMCM}

In a further step, the kinetic and potential energy have been determined for the 10-day model case in a similar way as Geller and Gong (2010) who used radiosonde data in the tropo- and lower stratosphere. The potential energy per unit mass has been derived from the temperature variations $T^{\prime}$ and the 10-day mean temperature per height $\bar{T}$ :

$E_{p o t}=\frac{1}{2} \frac{g^{2}}{N^{2}} \overline{\left(\frac{T^{\prime}}{\bar{T}}\right)^{2}}$

with the gravity acceleration $g$ and the Brunt-Väisälä frequency $N$. $N^{2}$ has been calculated for each $1 \mathrm{~km}$ height interval from the mean temperature gradient over a $6-\mathrm{km}$ height interval. For this case study, $N^{2}$ has a temporal mean value of $4 \times 10^{-4} \mathrm{~s}^{-2}$ in the mesosphere which agrees well with literature results and varies from about $2.5 \times 10^{-4} \mathrm{~s}^{-2}$ at around $80 \mathrm{~km}$ to $6 \times 10^{-4} \mathrm{~s}^{-2}$ at around $95 \mathrm{~km}$. The kinetic energy per unit mass has been calculated from the wind variations $u^{\prime}$ and $v^{\prime}$ :

$E_{k i n}=\frac{1}{2} \overline{\left(u^{\prime 2}+v^{\prime 2}\right)}$.

Here, overbars indicate temporal averages for the 10 days.

Fig. 7 (left) shows the 10-day mean vertical profiles of the kinetic, potential, and total energy per unit mass on a logarithmic scale in the mesopause region between 80 and $96 \mathrm{~km}$ with $1 \mathrm{~km}$ vertical resolution. The total energy per unit mass is the sum of kinetic and potential energy contributions: $E_{\text {tot }}=E_{\text {kin }}+E_{\text {pot }}$. Both the kinetic (dashed line) and the potential (solid line) energy per unit mass reveal a continuous increase with height with values of $E_{\text {pot }}$ being lower than those of $E_{\text {kin }}$. Values at $80 \mathrm{~km}$ are somewhat above $100 \mathrm{~J} / \mathrm{kg}$ for $E_{\text {pot }}$ and $200 \mathrm{~J} / \mathrm{kg}$ for $E_{k i n}$, respectively, and reach about $400 \mathrm{~J} / \mathrm{kg}\left(E_{\text {pot }}\right)$ and $500 \mathrm{~J} / \mathrm{kg}\left(E_{\text {kin }}\right)$ at about $96 \mathrm{~km}$. Hence, the total energy per unit mass increases continuously from about $300 \mathrm{~J} / \mathrm{kg}$ to almost $900 \mathrm{~J} / \mathrm{kg}$ in the displayed height range. This increase of the energy per unit mass results from the decrease in air density with height, i.e., the trend of $E_{\text {tot }}$ is in agreement with the expected exponential amplitude growth of the GW with height $\left(e^{z / H}\right.$, red solid line in the left part of Fig. 7) until the GW dissipate above about $86 \mathrm{~km}$. Then the slope of the energy becomes steeper than that of the $e^{z / H}$-line indicating an energy loss due to wave breaking (see e.g., Rauthe et al., 2008).

Furthermore, the ratio of kinetic to potential energy has been investigated. From linear GW theory this ratio is predicted to be equal to $\sim 5 / 3$ as a nominal average value (VanZandt, 1985). Indeed in Fig. 7 (right) it can be seen that the ratio $E_{\text {kin }} / E_{\text {pot }}$ only shows a minor deviation from this expected value.

In summary, the analyses presented in Section 3.1 generally confirm the approximate validity of linear wave theory for the KMCM data. Importantly, this confirmation requires an initial spectral analysis of the data to unravel effects of a superposition of several waves contributing to the overall variance. In the next section, the same methodology will now be applied to observations.

\subsection{Investigation of radar winds and lidar temperature}

In this section, horizontal wind data from radar measurements and temperature data from lidar measurements have been combined for the first time to test the validity of linear wave theory in the form of the polarization relations between wind and temperature variations as well as the relation between kinetic and potential energy. The following analysis is based on a continuous dataset from 11 to 13 October 2005 for which uninterrupted lidar observations were obtained.

\subsubsection{Time series analysis for radar and lidar measurements}

For an initial overview of the dominating wind and temperature conditions during the here discussed case study, Fig. 8 shows the MF radar zonal (a) and meridional wind (b). The dominating wind direction is westward and southward above about $80 \mathrm{~km}$ and eastward and northward at altitudes below. The mean prevailing temperature (Fig. 8d) in the MLT is about $170-200 \mathrm{~K}$ and decreases with height. The activity of tidal waves during the selected period is very weak as shown by the semidiurnal meridional tidal component (Fig. 8c). The general influence of the 8-h tide on the measurements will be discussed later in this section.

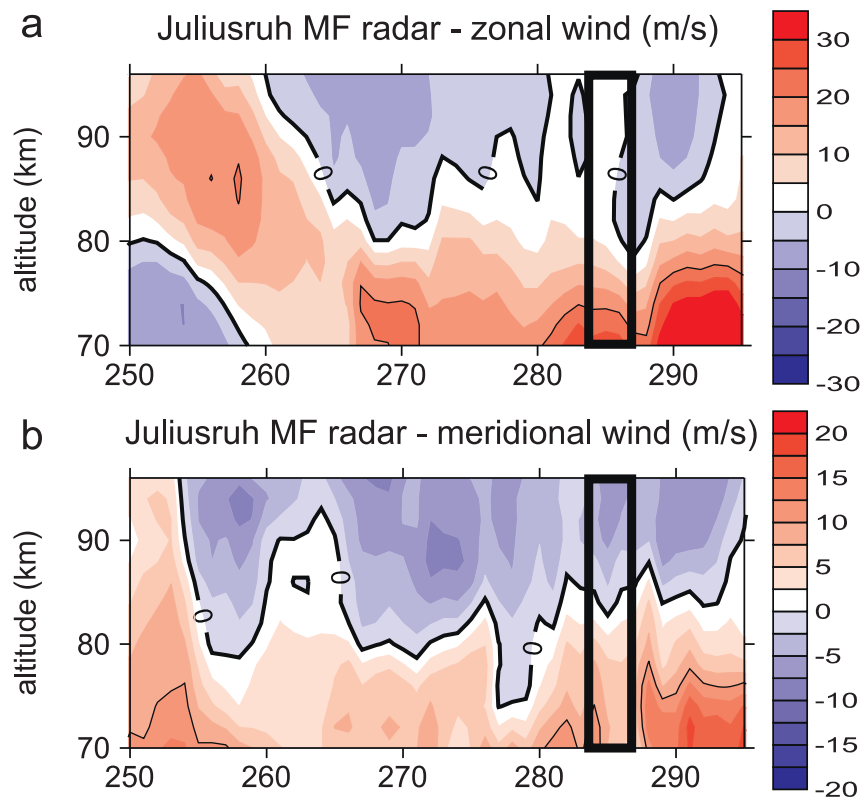

C Juliusruh MF radar - amp $12 \mathrm{~h}$ tide $\operatorname{mer}$ - $(\mathrm{m} / \mathrm{s})$
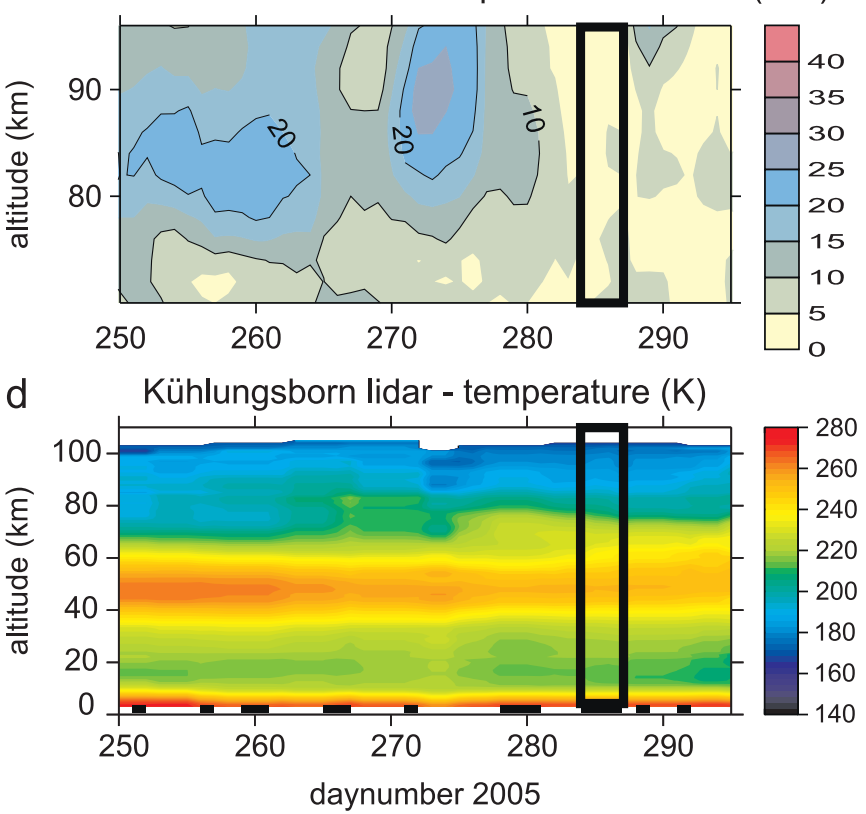

Fig. 8. Mean prevailing zonal (a) and meridional (b) wind (after removal of tides) and the amplitude of the 12-h tide of the meridional wind (c) from the MF radar measurements at Juliusruh as well as the mean temperature (d) from the lidar measurements at Kühlungsborn. Averages for 4 days (wind) and 10 days (temperature) are shown, shifted by 1 day each. The black lines in the lower part of $(d)$ indicate the original lidar measurement periods. Temperature data gaps are closed by the 10-day averaging procedure. The black boxes mark the time of data investigation of this study from 11 to 13 October 2005 . 


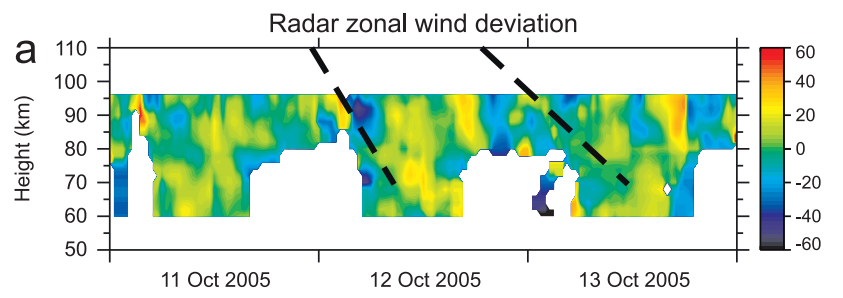

Radar meridional wind deviation
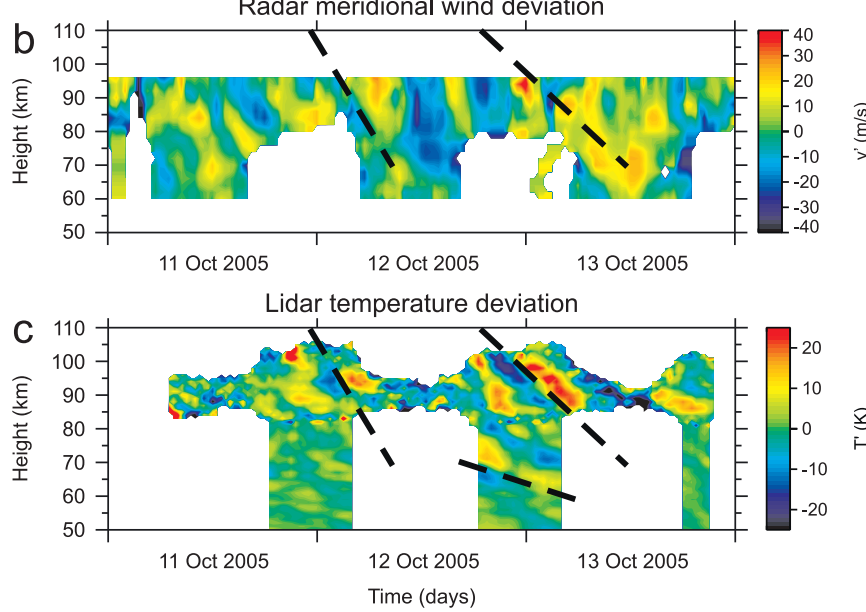

Fig. 9. Height-time cross-sections of the zonal (a) and meridional (b) wind variations from the MF radar at Juliusruh and of the temperature variations (c) from the $\mathrm{K}$ and RMR lidar at Kühlungsborn. The data of both radar and lidar measurements has a time resolution of $30 \mathrm{~min}$, integrated for $2 \mathrm{~h}$. The height resolution of temperature and wind is $1 \mathrm{~km}$ and $2 \mathrm{~km}$, respectively. Dashed lines show exemplary phase lines of waves occurring in all parameters at the same time.

In Fig. 9, the zonal (a) and meridional (b) wind variations and the temperature variations (c) (determined as deviations from daily means) are displayed. The means are calculated for a "lidar day", i.e., from noon of one day to noon of the subsequent day which had been referred to "nightly means" (e.g., Rauthe et al., 2006). The radar wind data is a part of the long continuous time series of radar measurements in the height range between 60 and $96 \mathrm{~km}$. The shown lidar temperatures are the dataset of this case study which covers almost three consecutive days. The temperature data is a composite of $\mathrm{K}$ lidar data from approximately 85-105 km height and RMR lidar data from the ground (here shown from $50 \mathrm{~km}$ on) up to about $90 \mathrm{~km}$ (see Section 2.1). The maximum height coverage of the lidar observations is only available during nighttime ( $\sim 18: 00 \mathrm{LT}$ to $04: 00 \mathrm{LT})$ as the signal-to-noise ratio is highest in the darkness. During daytime the $\mathrm{K}$ lidar temperatures are limited to about $85-95 \mathrm{~km}$. In contrast, the radar winds have their broadest height coverage (from 60 to about $96 \mathrm{~km}$ ) during daytime due to high ionization rates in the mesosphere whereas the nighttime winds are limited to approximately $80-96 \mathrm{~km}$. The wind variations vary in general between about $\pm 30 \mathrm{~m} / \mathrm{s}$ and the temperature variations between about $\pm 25 \mathrm{~K}$. The black dashed lines show exemplary phase lines of wave propagation in the wind and temperature fields. Just like in the case of the KMCM data, these phase lines steepen with increasing altitudes due to the effect of the background wind. It can be seen that it is ambiguous to observe an obvious monochromatic wave that is evident over several cycles. But suitable spectral analysis and band pass filtering make it possible to identify dominant wave components which can be traced over several cycles and checked for their agreement with linear wave theory.

As for the model data, dominant wave periods have been determined in the wind and temperature time series with a
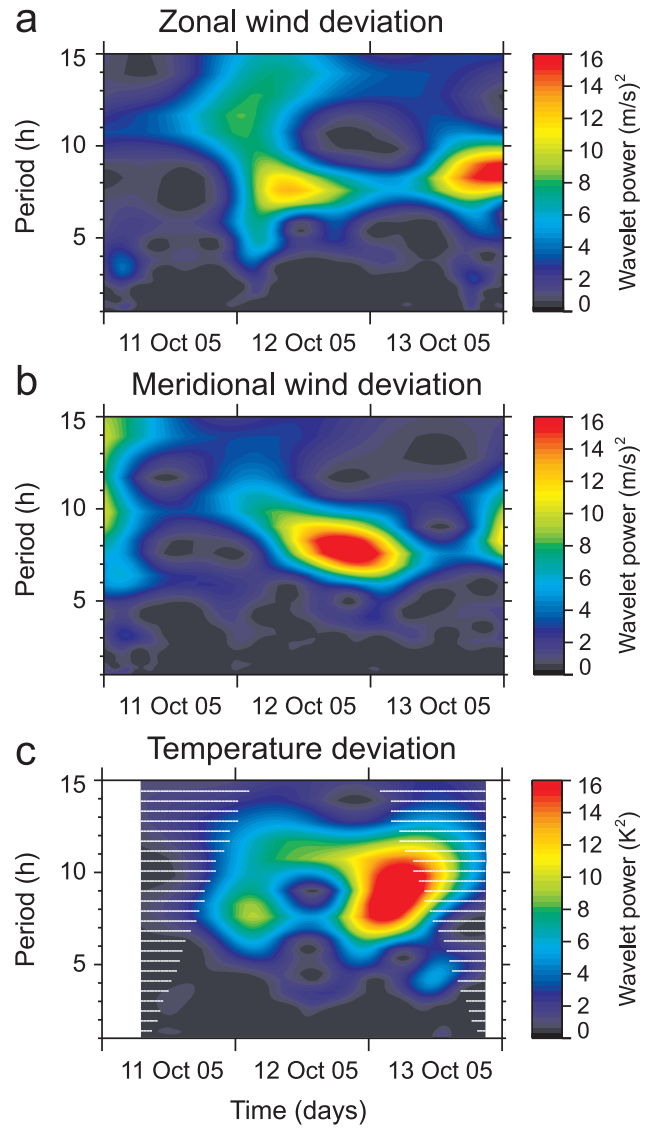

Fig. 10. Spectra of the zonal wind (a), meridional wind (b), and temperature (c) variations at $92 \mathrm{~km}$ height for radar and lidar measurements derived with the wavelet transformation. The white shading in (c) indicates the cone of influence where boundary effects occur due to the limited length of the time series.

wavelet analysis at $92 \mathrm{~km}$. At this height, the radar and lidar measurements are continuous over the whole 3-day period and, in general, reveal the largest wave amplitudes. In Fig. 10, the power spectra derived with a wavelet analysis for the zonal (a) and meridional (b) wind variations and the temperature variations (c) are shown. The spectra are displayed for periods from 1 to $15 \mathrm{~h}$ during the 3-day case study. In the spectrum of the zonal wind variations two maxima appear in the period range from about $6-11 \mathrm{~h}$. The major maximum appears in the second half of 13 October and the minor one in the morning and noon of 12 October. For the meridional wind variations, there exists just one maximum also for about $6-11 \mathrm{~h}$ period in the second half of 12 October and the morning of the following day which is of similar magnitude as the major maximum of the zonal wind variations. The spectrum of the temperature variations shows a weakly pronounced dipole structure similar to that from the zonal wind variations, but the major maximum covers a slightly broader period range and begins at the end of 12 October and lasts until noon of the following day. Overall, especially the wavelet analyses of meridional wind and temperature variations show a good agreement with dominant wave periods between 6 and $11 \mathrm{~h}$ around the transition from 12 to 13 October. Note that the spectra of the winds were determined by wavelet transform for extended time series to avoid effects by the "cone of influence" (COI). In contrast, the temperature time series is limited such that COI-effects must be taken into account.

Fig. 11 shows the comparison of the time series and Fourier power spectra for zonal wind, meridional wind, and temperature variations. The power spectra have corresponding dominant peaks in winds and temperature at 8 and $10 \mathrm{~h}$. To avoid that these 

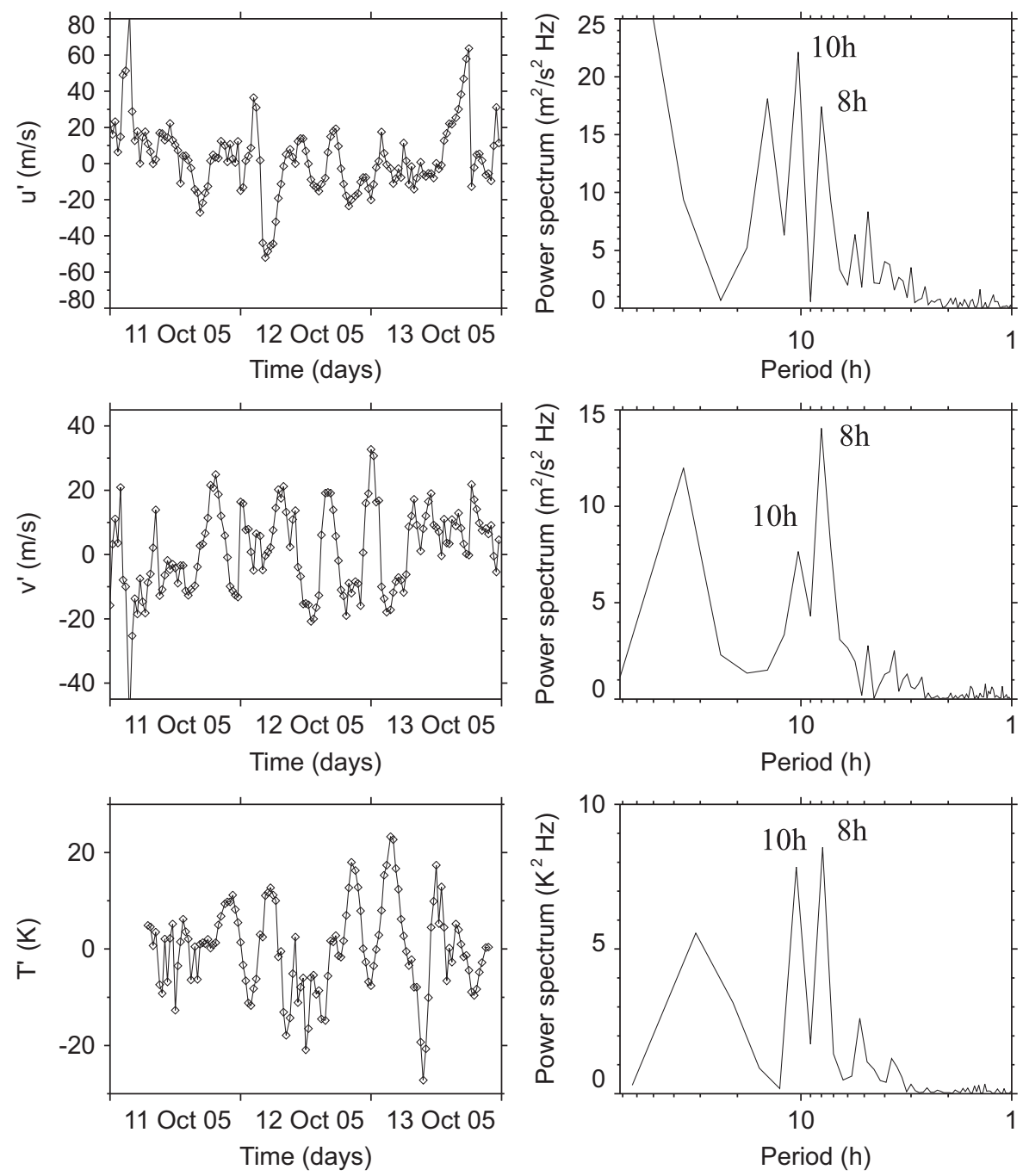

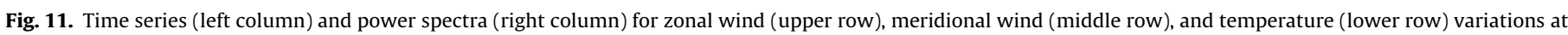
$92 \mathrm{~km}$ height for radar and lidar measurements. Dominant peaks of the power spectra are labeled.

variations are caused by tidal waves instead of GW, we calculated the wind variations for each day by a removal of the mean diurnal, semidiurnal and terdiurnal tidal component derived for groups of seven days (e.g., Hoffmann et al., 2010). Therefore we are confident that the dominant peak at $8 \mathrm{~h}$ is caused by GW and not the terdiurnal tide. Note, however, that the same tidal correction is not possible for the temperature data due to the shortness of the time series. On the other hand, our tidal analysis of the winds reveals very small amplitudes for the semidiurnal (see Fig. 8c) and terdiurnal tide (not shown) so that we also consider it unlikely that the temperature data is strongly influenced by this effect.

In Fig. 12, the filtered time series for zonal wind, meridional wind, and temperature variations are displayed. Here the time series filtering has been performed for 6-11 h (the dominant wave periods obtained from the wavelet analysis). It is noticeable that during the strongest wavelet power event around the transition from 12 to 13 October zonal and meridional wind variations only have a small phase shift with the zonal component following the meridional one. Furthermore, the filtered meridional wind variations are anticorrelated with the filtered temperature variations, i.e., the filtered $v^{\prime}$ is positive when the filtered $T^{\prime}$ is negative and vice versa which means that they have almost a phase shift of $180^{\circ}$. This is consistent with results of a wave parameter analysis (see below).

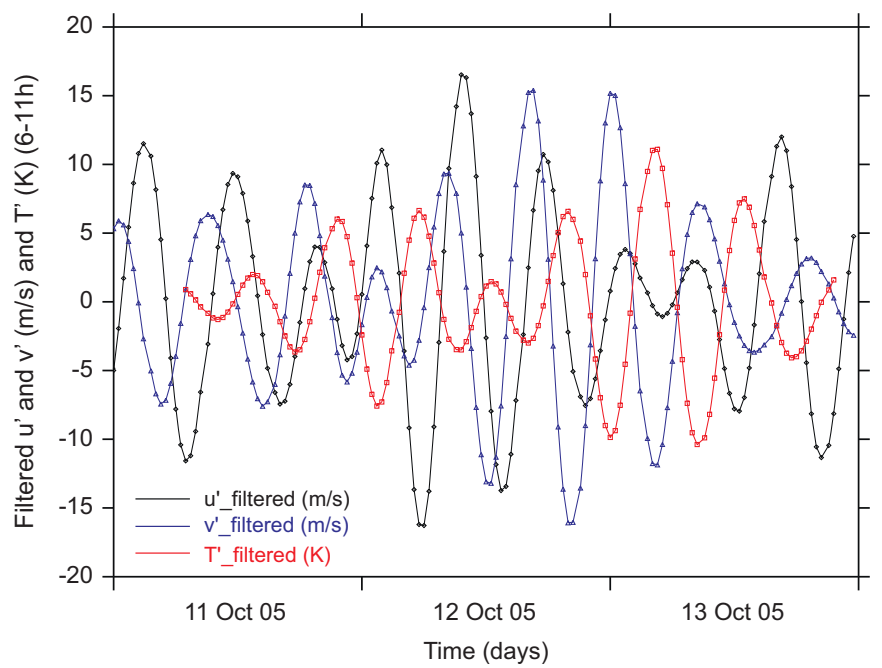

Fig. 12. Filtered time series for $6-11 \mathrm{~h}$ for zonal wind variations $u^{\prime}$ (black line), meridional wind variations $v^{\prime}$ (blue line), and temperature variations $T^{\prime}$ (red line) at $92 \mathrm{~km}$ height for radar and lidar measurements. During the time with strongest amplitudes (12-13 October 2005) $u^{\prime}$ follows $v^{\prime}$ while $v^{\prime}$ is proportional to $-T^{\prime}$. (For interpretation of the references to color in this figure caption, the reader is referred to the web version of this article.) 


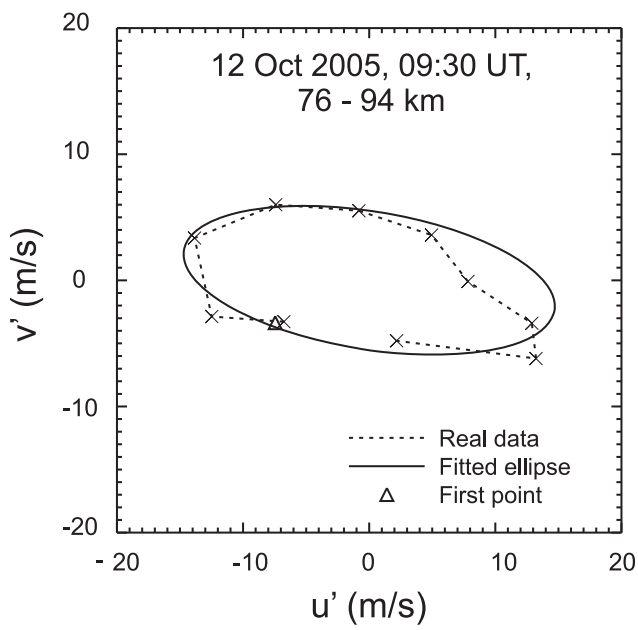

Fig. 13. Hodograph analysis for the MF radar at Juliusruh on 12 October 2005, 09:30 UT. The crosses on the dashed line indicate the observations between 76 and $94 \mathrm{~km}$ height with an altitude step of $2 \mathrm{~km}$, beginning at the point labeled by the triangle.

\subsubsection{Wave parameter analysis for radar and lidar measurements}

To test the validity of the polarization relations between wind and temperature (and hence of linear wave theory) for the radar and lidar observations, the same type of analysis has been applied to this data as for the case of KMCM data. In addition, we initially present a hodograph analysis (assuming the presence of one dominating GW) which is then generalized to a Stokes parameters analysis (which also allows the presence of multiple waves).

The hodograph analysis is commonly used to retrieve GW characteristics from vertical profiles of zonal and meridional wind fluctuations. In Fig. 13, the filtered zonal and meridional wind variations are displayed against each other at the period where the most intensive wave structures occur (12 October 2005, 09:30 UT). The individual filtered wind values from 76 to $94 \mathrm{~km}$ describe almost an ellipse (dashed line). The fitted ideal ellipse (solid line) under the theoretical assumption of the presence of one monochromatic GW is displayed as well. The ellipses provide strong evidence that the measurements are due to a GW. From the hodograph, several parameters can be derived such as the vertical sense of GW propagation (from the rotational sense of the ellipse), the direction of the horizontal wave propagation (that is parallel to the major axis of the ellipse for inertia GW which are strongly influenced by the Coriolis force and thus resulting in an elliptic hodograph (compare Cot and Barat, 1986)), the vertical wavelength, and the intrinsic frequency (from the ratio of the major to the minor axis of the ellipse). The azimuth propagation angle is measured anti-clockwise beginning at eastern direction. Here the clockwise rotation of the hodograph indicates an upward propagating wave (for the northern hemisphere). The inclination of the major axis of the ellipse is $\Theta_{\text {hodo }} \approx-9.25^{\circ}$ which corresponds to a propagation in approximately zonal direction with an uncertainty of $180^{\circ}$. The derived intrinsic frequency is equal to an intrinsic period of $5.4 \mathrm{~h}$. The remaining wave parameters are estimated by first fixing the vertical wavelength by means of a rotary-spectra analysis of the wind data, and then using the Doppler and dispersion relation. The resulting zonal wave number is $k=-0.40 \times 10^{-5} \mathrm{~m}^{-1}$, the meridional wave number is $l=0.65 \times$ $10^{-6} \mathrm{~m}^{-1}$, and the vertical wave number is $m=-0.39 \times 10^{-3} \mathrm{~m}^{-1}$. The polarization relations between temperature and zonal (meridional) wind variations have then been calculated according to the right hand side of Eq. (8) (Eq. (10)) with an observed $N^{2}=3.8 \times$
$10^{-4} \mathrm{~s}^{-2}$ for the whole 3 -day case study and $T_{m}=175.5 \mathrm{~K}$ for 12 October 2005, 06-18 UT. Both values were determined between 74 and $94 \mathrm{~km}$. The results are $T^{\prime} / u^{\prime}=0.23 \mathrm{~K} /(\mathrm{m} / \mathrm{s})$ and $T^{\prime} / v^{\prime}=$ $0.57 \mathrm{~K} /(\mathrm{m} / \mathrm{s})$, respectively. Note that the presented hodograph analysis represents a snapshot at one particular time and is based on the assumption of a dominating monochromatic wave. However, the spectra in Fig. 11 show the presence of more than one wave period.

In order to get a statistical description of all present waves during the strongest wave activity we also checked our hodograph results with the Stokes parameters analysis as for the case of KMCM. The parameters were averaged for the altitudes from 74 to $94 \mathrm{~km}$ for a period of $12 \mathrm{~h}$ (06-18 UT) on 12 October 2005. Indeed, the derived distribution of the $\mathrm{GW}$ propagation direction in Fig. 14(a) with $\Theta=2.25^{\circ}$ qualitatively confirms the propagation direction derived from the hodograph analysis at the selected time (12 October 2005, 09:30 UT). However, the mean normalized wave intensity (Fig. 14b) indicates a high temporal variability. This also leads to time dependent ellipse axial ratios and variable polarization degrees (Fig. 14c) with a mean phase difference between $u^{\prime}$ and $v^{\prime}$ of $51.7^{\circ}$ which is also evident in the timing between $u^{\prime}$ and $v^{\prime}$ in Fig. 12. Here we considered waves with total variance $I>0.3$ and an axial ratio $R>0.2$. Again, the remaining wave parameters are estimated by first fixing the vertical wavelength by means of a rotary-spectra analysis of the wind data, and then by using the Doppler and dispersion relation. This yields $k=-0.41 \times 10^{-5} \mathrm{~m}^{-1}, l=-0.16 \times 10^{-6} \mathrm{~m}^{-1}$, and $m=-0.39 \times 10^{-3} \mathrm{~m}^{-1}$. Evaluating again the right hand sides of Eqs. (8) and (10) yields the values $T^{\prime} / u^{\prime}=0.14 \mathrm{~K} /(\mathrm{m} / \mathrm{s}$ ) and $T^{\prime} / v^{\prime}=0.61 \mathrm{~K} / \mathrm{m} / \mathrm{s}$, respectively. A final summary table of the retrieved parameters from hodograph and Stokes parameters analysis for the observations is given in Table 1.

Deviations between single parameters from the two different analysis methods may occur due to the fact that the properties of atmospheric GW as intrinsic period, wavelength and propagation direction are carried out with different limitations depending on the methods as shown by Lue and Kuo (2012). They tested different analysis methods with numerical data and stated for instance that hodograph analysis is accurate in case of one monochromatic wave whereas for a composite of upward and downward propagating waves the results become erroneous. In contrast, Stokes parameters method gives statistically meaningful values irrespective of the vertical sense of propagation. However, such evaluations using the observational data presented here are beyond the scope of the present paper and will be considered in future work.

When evaluating the left hand sides of the Eqs. (8) and (10) directly from the 12-h peak amplitudes of the filtered time series (Fig. 12), shifted by $30 \mathrm{~min}$ (compare Section 3.1.2), the results for 12 October 2005, 06-18 UT, are $T^{\prime} / u^{\prime}=0.41 \mathrm{~K} /(\mathrm{m} / \mathrm{s})$ and $T^{\prime} / v^{\prime}=0.46 \mathrm{~K} /(\mathrm{m} / \mathrm{s})$ with standard deviations of $0.11 \mathrm{~K} /(\mathrm{m} / \mathrm{s})$ and $0.12 \mathrm{~K} /(\mathrm{m} / \mathrm{s})$, respectively.

Finally, we checked the influence of the temporal variations of the axial ratios and propagation directions derived by the Stokes parameters analysis (Fig. 14) on our results. With $\Delta R=0.067$ as standard error of the derived mean value of axial ratio $R$ (Eq. (2)) and $\Delta \Theta=13.88^{\circ}$ as standard error of the mean propagation direction, the zonal wave number $k$ varies only between $-0.395 \times$ $10^{-5} \mathrm{~m}^{-1}$ and $-0.41 \times 10^{-5} \mathrm{~m}^{-1}$ whereas the meridional wave number $l$ shows more variations between $-0.11 \times 10^{-5} \mathrm{~m}^{-1}$ and $0.81 \times 10^{-6} \mathrm{~m}^{-1}$. The stronger deviations of the meridional wave numbers are mainly related to the dominating wave propagation in zonal direction as roughly confirmed by an error propagation analysis applied on Eqs. (8) and (10). This leads to variations of the $T^{\prime} / u^{\prime}$-values only by $\pm 0.01 \mathrm{~K} /(\mathrm{m} / \mathrm{s})$, whereas the $T^{\prime} / v^{\prime}$-values show variations by $\pm 0.19 \mathrm{~K} /(\mathrm{m} / \mathrm{s})$. The overall results are summarized in Table 2. 


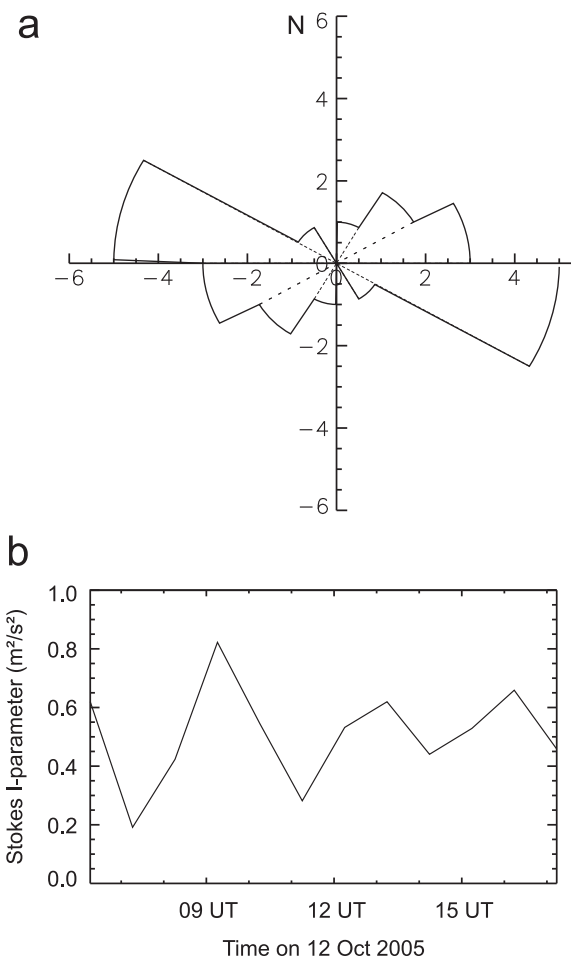

Mean ellipse axial ratio $\mathrm{R}=0.23$

Mean major axis orientation $=2.25^{\circ}$

Mean degree of polarization $d=0.43$

Mean phase difference $=51.7^{\circ}$

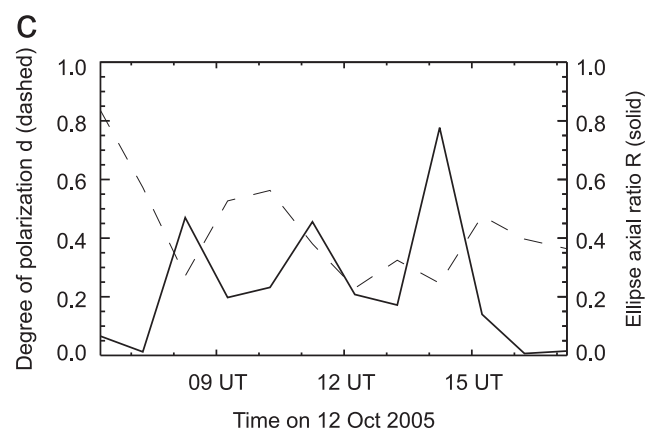

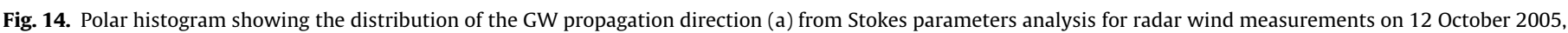

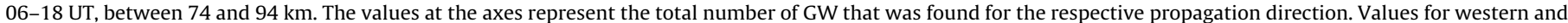

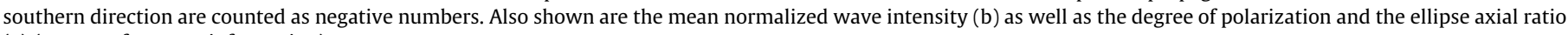
(c) (see text for more information).

Table 1

Overview of the retrieved parameters from hodograph and Stokes parameters analysis.

\begin{tabular}{llllll}
\hline Method & $\begin{array}{l}\text { Intrinsic } \\
\text { period } \\
(\mathrm{h})\end{array}$ & $k$ & \multicolumn{2}{l}{ Wavenumbers $\left(\mathrm{m}^{-1}\right)$} & $\begin{array}{l}\text { Azimuth } \\
\text { angle } \theta \\
\text { (deg.) }\end{array}$ \\
\cline { 3 - 6 } & $k$ & $l$ & $m$ & \\
\hline Hodograph & 5.4 & $-0.40 \times 10^{-5}$ & $0.65 \times 10^{-6}$ & $-0.39 \times 10^{-3}$ & -9.25 \\
Stokes & 3.4 & $-0.41 \times 10^{-5}$ & $-0.16 \times 10^{-6}$ & $-0.39 \times 10^{-3}$ & 2.25 \\
\hline
\end{tabular}

Table 2

Ratio of observational temperature and wind variations according to different methods.

\begin{tabular}{lll}
\hline Method & $T^{\prime} / u^{\prime}(\mathrm{K} /(\mathrm{m} / \mathrm{s}))$ & $T^{\prime} / v^{\prime}(\mathrm{K} /(\mathrm{m} / \mathrm{s}))$ \\
\hline Stokes & $0.14 \pm 0.01$ & $0.61 \pm 0.19$ \\
Amplitudes & $0.41 \pm 0.11$ & $0.46 \pm 0.12$ \\
\hline
\end{tabular}

Table 2 reveals that the two statistical methods (Stokes parameters analysis and mean 12 -h peak amplitudes of the filtered time series) yield comparable values with $T^{\prime} / v^{\prime}$ showing a better agreement as compared to $T^{\prime} / u^{\prime}$ where a deviation of a factor of $\sim 3$ is observed. Note that we have checked whether this larger discrepancy for the $T^{\prime} / u^{\prime}$-values could have been caused by the fact that the observations comprise two waves which are not well separated by our chosen band pass filter window from 6 to 11 hours. We have repeated a similar analysis as shown above trying to separate the spectral peaks at 8 and $10 \mathrm{~h}$. This, however, gave us results comparable to the ones shown in Table 2 . Therefore, we conclude that this superposition is not the cause of the observed discrepancy for $T^{\prime} / u^{\prime}$.
3.2.3. Kinetic and potential energy for radar and lidar measurements As for the analysis of the model dataset, kinetic and potential energy per unit mass have been determined for the radar and lidar measurements. Again Eqs. (11) and (12) are used for the energy calculations with 1-day mean temperatures $\bar{T}$ per height and wind and temperature deviations derived from 1-day means. The BruntVäisälä frequency has been derived from temperature gradients calculated as 6-km averages for each 1-km height interval as a 3-day mean. The values for $N^{2}$ are similar to those obtained from the KMCM temperature data between 80 and $96 \mathrm{~km}$, increasing slowly from $\sim 3.5 \times 10^{-4} \mathrm{~s}^{-2}$ to $\sim 5 \times 10^{-4} \mathrm{~s}^{-2}$ (not shown here).

In Fig. 15 (left) the 3-day mean vertical profiles of upper mesospheric kinetic, potential, and total energy per unit mass are displayed. As the vertical resolution of the radar and lidar data is different ( $2 \mathrm{~km}$ for radar and $1 \mathrm{~km}$ for lidar) the potential energy can be calculated for each kilometer, whereas the kinetic energy can only be calculated every $2 \mathrm{~km}$. To illustrate the energies in an analogue and comparable way we chose a uniform vertical scale. Thus we adapted the vertical resolution of the potential energy to that of the kinetic energy by using 3-km averages of the potential energy data shifted by $2 \mathrm{~km}$. Both the kinetic (dashed line) and the potential (solid line) energy increase with height. The values at $80 \mathrm{~km}$ are $\sim 80 \mathrm{~J} / \mathrm{kg}$ for $E_{\text {pot }}$ and $150 \mathrm{~J} / \mathrm{kg}$ for $E_{\text {kin }}$ and reach about $310 \mathrm{~J} / \mathrm{kg}$ $\left(E_{p o t}\right)$ and $230 \mathrm{~J} / \mathrm{kg}\left(E_{\text {kin }}\right)$ around $96 \mathrm{~km}$. Except for the lowest shown heights the values of the kinetic energy are somewhat smaller than those of the potential energy which is in contrast to the model data. We suspect that this is due to the coarser vertical resolution of the radar data (mentioned before). Such a dependence on the vertical resolution is supported by the investigation of different "observational filters" (e.g., Alexander, 1998) and by comparison of kinetic energy spectra calculated from several general circulation models with different vertical resolutions (e.g., Koshyk et al., 1999). In addition, note that lidar and radar have very different horizontal measurement domains, i.e., the horizontal extent of the measurement 

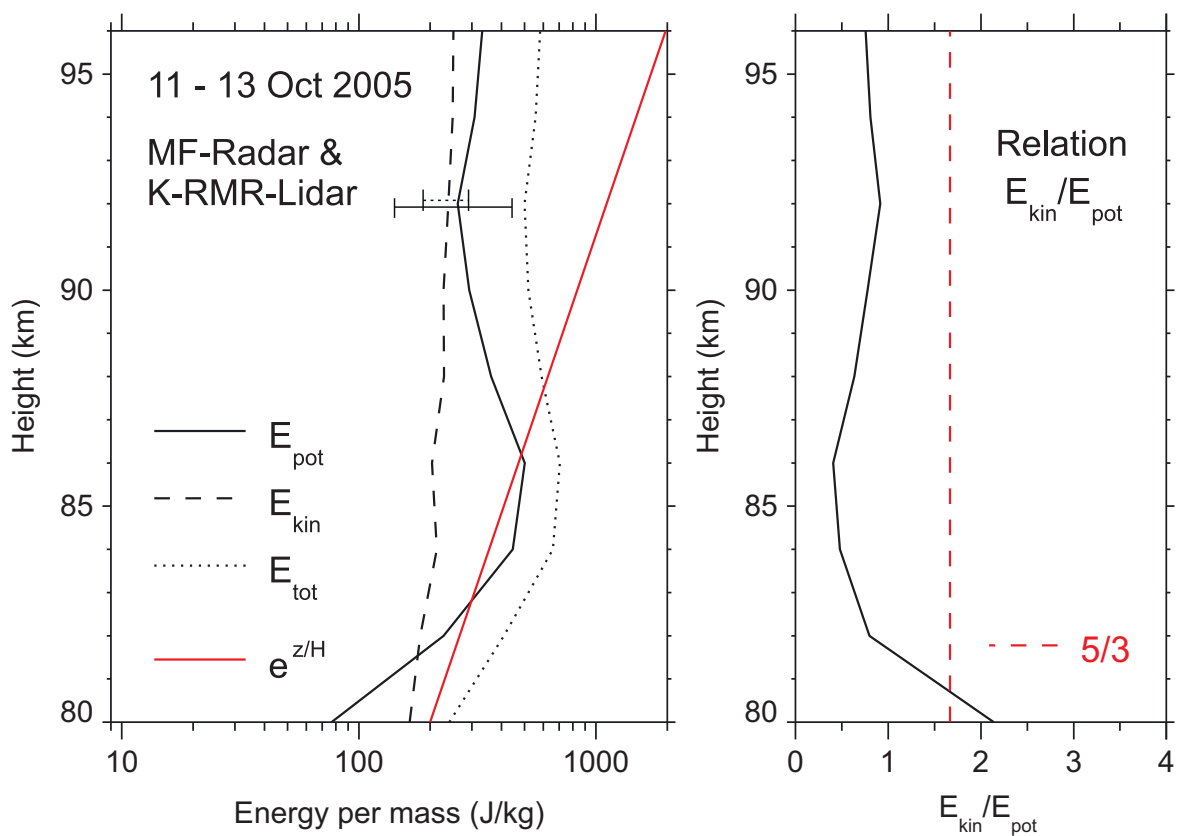

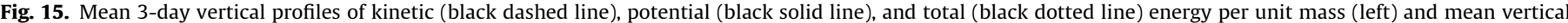

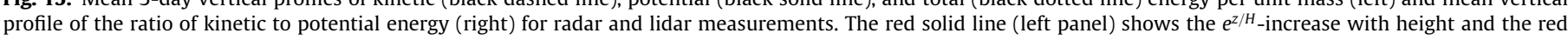

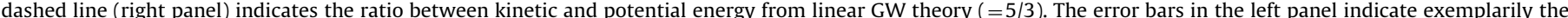

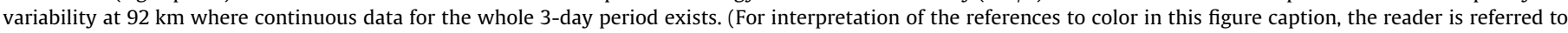
the web version of this article.)

volume of the MF radar is much larger than for the lidar. Hence, the ratio of kinetic to potential energy of the three considered days (Fig. 15 (right)) is somewhat lower than the predicted value of $5 / 3$ indicating, perhaps, that the MF-radar measurements are underestimating the true wave amplitudes. Nevertheless the ratio of kinetic to potential energy is relatively constant with height and the vertical gradient of the total energy follows the $e^{z / H}$-line in the lower shown heights. At higher altitudes GW breaking begins as expected based on simple energy conservation arguments. Hence, above about $86 \mathrm{~km}$ the gradients of the energy profiles become again steeper than the gradient of the $e^{z / H}$-line showing the loss in energy due to $\mathrm{GW}$ dissipation. However, due to the shortness of the investigated time series consisting only of 3 days an error estimation for the energies is only possible at the used altitude at $92 \mathrm{~km}$ where continuous measurements over the whole 3-day period exist.

\section{Conclusions}

In the current manuscript, we have presented a test of linear gravity wave (GW) theory based on simultaneous measurements of horizontal winds from a medium frequency (MF) radar at Juliusruh $\left(54.6^{\circ} \mathrm{N}, 13.4^{\circ} \mathrm{E}\right)$ and temperatures from combined Potassium $(\mathrm{K})$ and Rayleigh-Mie-Raman (RMR) lidars at Kühlungsborn $\left(54.1^{\circ} \mathrm{N}, 11.8^{\circ} \mathrm{E}\right)$. Before analyzing our experimental dataset for its fit to expectations from linear GW theory, the chosen methodology has been tested with model data from the Kühlungsborn Mechanistic general Circulation Model (KMCM). With a high spatial resolution this model resolves waves with horizontal wavelengths down to $\sim 350 \mathrm{~km}$ explicitly and thus yields a semi-realistic wave motion field. This allows us to give evidence for the validity of polarization relations based on linear wave theory with Stokes parameters analysis of filtered time series of GW-induced wind and temperature fluctuations in comparison to wave amplitudes directly retrieved from the filtered time series for a model case study. Indeed, the same methodology applied to the observations yields similarly conclusive results (at least when taking into account the errors of the observations) thus generally supporting the applicability of linear wave theory to mesospheric observations. The investigations have been completed by a comparison of kinetic and potential energy per unit mass for model and measured data showing a vertical increase in accordance with the exponential amplitude growth due to decreasing density up to about $86 \mathrm{~km}$. Above that height, GW dissipation occurs which is indicated in weaker energy increase with height. In addition, the ratio of kinetic and potential energy roughly follows the expectations from linear wave theory, lending support for the validity of this approach. Moderate observed deviations from expectations of linear wave theory could be caused by a systematic underestimation of the winds (and their variations) due to the coarse altitude resolution of the radar, or by some violation of the linearity of the observed waves (e.g., we cannot exclude a superposition of different waves or any non-linear interactions between various waves which is not considered here). Clearly, this issue should be scrutinized with more and independent observations which should ideally be conducted in the same atmospheric volume and with an identical spatial and temporal resolution using a combined Doppler wind and Rayleigh lidar system (e.g., Baumgarten, 2010).

\section{Acknowledgments}

We thank Dieter Keuer for his support taking care of the MF radar at Juliusruh and Josef Höffner for making the $\mathrm{K}$ lidar data available. We are grateful for the support by the "International Leibniz Graduate School for Gravity Waves and Turbulence in the Atmosphere and Ocean" (ILWAO) funded by the Leibniz Association (WGL).

\section{References}

Alexander, M.J., 1998. Interpretations of observed climatological patterns in stratospheric gravity wave variance. Journal of Geophysical Research 103 , 8627-8640, http://dx.doi.org/10.1029/97JD03325. 
Alexander, M.J., Geller, M., McLandress, C., Polavarapu, S., Preusse, P., Sassi, F., Sato, K., Eckermann, S., Ern, M., Hertzog, A., Kawatani, Y., Pulido, M., Shaw, T.A., Sigmond, M., Vincent, R., Watanabe, S., 2010. Recent developments in gravitywave effects in climate models and the global distribution of gravity-wave momentum flux from observations and models. Quarterly Journal of the Royal Meteorological Society 136, 1103-1124.

Alpers, M., Eixmann, R., Fricke-Begemann, C., Gerding, M., Höffner, J., 2004. Temperature lidar measurements from 1 to $105 \mathrm{~km}$ altitude using resonance, Rayleigh, and rotational Raman scattering. Atmospheric Chemistry and Physics 4 (3), 793-800.

Baumgarten, G., 2010. Doppler Rayleigh/Mie/Raman lidar for wind and temperature measurements in the middle atmosphere up to $80 \mathrm{~km}$. Atmospheric Measurement Techniques 3, 1509-1518, http://dx.doi.org/10.5194/amt-31509-2010.

Becker, E., 2009. Sensitivity of the upper mesosphere to the Lorenz energy cycle of the troposphere. Journal of the Atmospheric Sciences 66, 647-666, http://dx.d oi.org/10.1175/2008JAS2735.1.

Becker, E., 2011. Dynamical control of the middle atmosphere. Space Science Reviews , http://dx.doi.org/10.1007/s11214-011-9841-5.

Chun, H.-Y., Kim, Y.-H., 2008. Secondary waves generated by breaking of convective gravity waves in the mesosphere and their influence in the wave momentum flux. Journal of Geophysical Research 113, D23107, http://dx.doi.org/10.1029/ 2008JD009792.

Cot, C., Barat, J., 1986. Wave-turbulence interaction in the stratosphere: A case study. Journal of Geophysical Research 91, 2749-2756.

Eckermann, S.D., Vincent, R., 1989. Falling sphere observations gravity waves motions in the upper stratosphere over Australia. Pure and Applied Geophysics $130,509-532$.

Eckermann, S.D., 1995. Effect of background winds on vertical wavenumber spectra of atmospheric gravity waves. Journal of Geophysical Research 100, 14,097-14,112.

Eckermann, S.D., 1996. Hodographic analysis of gravity waves: relationships among Stokes parameters, rotary spectra and cross-spectral methods. Journal of Geophysical Research 101, 19,169-19,174.

Ern, M., Preusse, P., Alexander, M.J., Warner, C.D., 2004. Absolute values of gravity wave momentum flux derived from satellite data. Journal of Geophysical Research 109, D20103, http://dx.doi.org/10.1029/2004JD004752.

Ern, M., Preusse, P., Gille, J.C., Hepplewhite, C.L., Mlynczak, M.G., Russell III, J.M., Riese, M., 2011. Implications for atmospheric dynamics derived from global observations of gravity wave momentum flux in stratosphere and mesosphere. Journal of Geophysical Research 116, D19107. http://dx.doi.org/10.1029/ 2011JD015821.

Fritts, D.C., Alexander, M.J., 2003. Gravity wave dynamics and effects in the middle atmosphere. Reviews of Geophysics 41 (1), http://dx.doi.org/10.1029/ 2001RG000106 3/1-64.

Gardner, C.S., Liu, A.Z., 2007. Seasonal variations of the vertical fluxes of heat and horizontal momentum in the mesopause region at starfire optical range, New Mexico. Journal of Geophysical Research 112 (D9), D09113, http://dx.doi.org/ 10.1029/2005JD006179.

Geller, M.A., Gong, J., 2010. Gravity wave kinetic, potential, and vertical fluctuation energies as indicators of different frequency gravity waves. Journal of Geophysical Research 115, D11111, http://dx.doi.org/10.1029/2009JD012266.

Gerding, M., Höffner, J., Lautenbach, J., Rauthe, M., Lübken, F.-J., 2008. Seasonal variation of nocturnal temperatures between 1 and $105 \mathrm{~km}$ altitude at $54 . \mathrm{N}$ observed by lidar. Atmospheric Chemistry and Physics 8, 7465-7482.

Gonzalez, N., Hauchecorne, A., Kirkwood, S., Lübken, F.-J., Manson, A.H., Mourier, A., Schmidlin, F.J., Schminder, R., Kürschner, D., Singer, W., Widdel, H.-U., 1994 Intercomparisons of simultaneous remote and in situ wind measurements. Journal of Atmospheric and Terrestrial Physics 56 (13-14), 1985-2001.

Gossard, E.E., Hooke, W.H., 1975. Waves in the atmosphere. In: Developments in Atmospheric Science, vol. 2. Elsevier Science, New York, pp. 456.

Hines, C.O., 1960. Internal atmospheric gravity waves at ionospheric heights. Canadian Journal of Physics 38, 1441-1481.

Hoffmann, P., Becker, E., Singer, W., Placke, M., 2010. Seasonal variation of mesospheric waves at northern middle and high latitudes. Journal of Atmospheric and SolarTerrestrial Physics 72, 1068-1079, http://dx.doi.org/10.1016/j.jastp.2010.07.002.

Keuer, D., Hoffmann, P., Singer, W., Bremer, J., 2007. Long-term variations of the mesospheric wind field at mid-latitudes. Annales Geophysicae 25 (8), 1779-1790.
Koshyk, J.N., Boville, B.A., Hamilton, K., Manzini, E., Shibata, K., 1999. Kinetic energy spectrum of horizontal motions in middle-atmosphere models. Journal of Geophysical Research 104, 27,177-27,190, http://dx.doi.org/10.1029/ 1999JD900814.

Lue, H.Y., Kuo, F.S., 2012. Comparative studies of methods of obtaining AGW's propagation properties. Annales Geophysicae 30, 557-570.

Nakamura, T., Higashikawa, A., Tsuda, T., Matsushita, Y., 1999. Seasonal variations of gravity wave structures in $\mathrm{OH}$ airglow with a CCD imager at Shigaraki. Earth, Planets and Space 51 (7-8), 897-906.

Placke, M., Hoffmann, P., Becker, E., Jacobi, Ch., Singer, W., Rapp, M., 2011. Gravity wave momentum fluxes in the MLT-Part II: meteor radar investigations at high and midlatitudes in comparison with modeling studies. Journal of Atmospheric and Solar-Terrestrial Physics 73, 911-920, http://dx.doi.org/ 10.1016/j.jastp.2010.05.007.

Preusse, P., Eckermann, S.D., Offermann, D., 2000. Comparisons of global distributions of zonal-mean gravity wave variance inferred from different satellite instruments. Geophysical Research Letters 27 (23), 3877-3880, http://dx.doi.org/10.1029/ 2000 GL011916.

Rauthe, M., Gerding, M., Höffner, J., Lübken, F.-J., 2006. Lidar temperature measurements of gravity waves over Kühlungsborn $\left(54^{\circ} \mathrm{N}\right)$ from 1 to $105 \mathrm{~km}$ : a wintersummer comparison. Journal of Geophysical Research 111 (D24), D24108, http://dx.doi.org/10.1029/2006JD007354.

Rauthe, M., Gerding, M., Lübken, F.-J., 2008. Seasonal changes in gravity wave activity measured by lidars at mid-latitudes. Atmospheric Chemistry and Physics 8, 6775-6787.

Serafimovich, A., Hoffmann, P., Peters, D., Lehmann, V., 2005. Investigation of inertia-gravity waves in the upper troposphere/lower stratosphere over Northern Germany observed with collocated VHF/UHF radars. Atmospheric Chemistry and Physics 5, 295-310.

Serafimovich, A., Zülicke, C., Hoffmann, P., Peters, D., Dalin, P., Singer, W., 2006. Inertia gravity waves in the upper troposphere during the MaCWAVE winter campaign, Part II: radar investigations and modelling studies. Annales Geophysicae 24, 2863-2875.

She, C.Y., Yu, J.R., Huang, J.W., Nagasawa, C., 1991. Na temperature lidar measurements of gravity wave perturbations of wind, density and temperature in the mesopause region. Geophysical Research Letters 18 (7), 1329-1331.

She, C.Y., Yu, J.R., 1994. Simultaneous three-frequency Na lidar measurements of radial wind and temperature in the mesopause region. Geophysical Research Letters 21 (17), 1771-1774.

Suzuki, S., Nakamura, T., Ejiri, M.K., Tsutsumi, M., Shiokawa, K., Kawahara, T.D., 2010 Simultaneous airglow, lidar, and radar measurements of mesospheric gravity waves over Japan. Journal of Geophysical Research 115, D24113, http://dx.doi.org/ 10.1029/2010JD014674.

Torrence, C., Compo, G.P., 1998. A practical guide to wavelet analysis. Bulletin of the American Meteorological Society 79 (1), 61-78.

Vadas, S.L., Yue, J., She, C.-Y., Stamus, P.A., Liu, A.Z., 2009. A model study of the effects of winds on concentric rings of gravity waves from a convective plume near Fort Collins on 11 May 2004. Journal of Geophysical Research 114, D06103, http://dx.doi.org/10.1029/2008JD010753.

VanZandt, T.E., 1985. A model for gravity wave spectra observed by Doppler sounding systems. Radio Science 20 (6), 1323-1330.

Vincent, R.A., Fritts, D.C., 1987. A climatology of gravity wave motions in the mesopause region at Adelaide, Australia. Journal of the Atmospheric Sciences 44 (4), 748-760.

Ward, W.E., Oberheide, J., Goncharenko, L.P., Nakamura, T., Hoffmann, P., Singer, W., Chang, L.C., Du, J., Wang, D.-Y., Batista, P., Clemesha, B., Manson, A.H., Riggin, D.M., She, C.-Y., Tsuda, T., Yuan, T., 2010. On the consistency of model, ground-based, and satellite observations of tidal signatures: initial results from the CAWSES tidal campaigns. Journal of Geophysical Research 115, D07107, http://dx.doi.org/10.1029/2009JD012593.

Wüst, S., Bittner, M., 2006. Non-linear resonant wave-wave interaction (triad): case studies based on rocket data and first application to satellite data. Journal of Atmospheric and Solar-Terrestrial Physics 68 (9), 959-976, http://dx.doi.org/ 10.1016/j.jastp.2005.11.011.

Zink, F., 2000. Gravity Waves and Turbulence in the Lower Atmosphere. Ph.D. Thesis. University of Adelaide, Australia. 